Supporting Information for

\title{
Anisotropic, Degradable Polymer Assemblies Driven by a Rigid Hydrogen-Bonding Motif That Induce Shape-Specific Cell Responses
}

Kazuki Fukushima, ${ }^{* 1,2}$ Kodai Matsuzaki, ${ }^{1}$ Masashi Oji, ${ }^{1}$ Yuji Higuchi, ${ }^{3}$ Go Watanabe, ${ }^{4}$ Yuki Suzuki, ${ }^{5}$ Moriya Kikuchi, ${ }^{1}$ Nozomi Fujimura, ${ }^{1}$ Naofumi Shimokawa, ${ }^{6}$ Hiroaki Ito, ${ }^{7}$ Takashi Kato, ${ }^{2}$ Seigou Kawaguchi, ${ }^{*}$, and Masaru Tanaka ${ }^{*, 8}$

${ }^{1}$ Department of Polymer Science and Engineering, Yamagata University

${ }^{2}$ Department of Chemistry and Biotechnology, School of Engineering, The University of Tokyo

${ }^{3}$ Institute for Solid State Physics, The University of Tokyo

${ }^{4}$ Department of Physics, School of Science, Kitasato University

${ }^{5}$ Frontier Research Institute for Interdisciplinary Sciences, Tohoku University

${ }^{6}$ School of Materials and Science, Japan Advanced Institute of Science and Technology

${ }^{7}$ Department of Physics, Chiba University

${ }^{8}$ Institute for Materials Chemistry and Engineering, Kyushu University

*Corresponding Authors: k_fukushima@chembio.t.u-tokyo.ac.jp (K.F.), skawagu@yz.yamagata-u.ac.jp (S.K.), and masaru tanaka@ms.ifoc.kyushu-u.ac.jp (M.T.)

\section{Contents:}

Additional experimental procedures

Figures S1 - S18

${ }^{1}$ H NMR spectra of PEG-UBA-OH (3), 1a, 1b, and 1c 
Materials. Poly(ethylene glycol) methyl ether (mPEG-OH; $M_{\mathrm{n}}=5000$ ), methoxypolyethylene glycol amine (PEG-NH $2 ; M_{\mathrm{n}}=5,000$ ), and 1,5,7-triazabicyclo[4.4.0]dec-5-ene (TBD) were purchased from Sigma-Aldrich Japan (Tokyo). Benzoic acid, dichloromethane (DCM), diethyl ether, methanol, $N, N$ Dimethyl formamide (DMF), tetrahydrofuran (THF), and hexane were purchased from Kanto Chemical (Tokyo, Japan). Triethylamine and 2-propanol were purchased from FUJIFILM Wako Pure Chemicals (Tokyo, Japan). p-Xylenediamine, methyl-4-(hydroxymethyl)benzoate, bis(pentafluorophenyl)carbonate (PFC), $\varepsilon$-caprolactone (CL), diphenyl phosphate (DPP), trimethylene carbonate (TMC), and toluene were purchased from Tokyo Chemical Industry (Tokyo, Japan). L-lactide (LLA) and D-lactide (DLA) were provided from Purac. Dehydrated DCM and THF were provided through a Solvent-Supply system (Kanto Chemical). mPEG-OH and PEG-NH 2 were dried azeotropically with toluene before use. 1-(3,5bis(trifluoromethyl)phenyl)-3-cyclohexyl-2-thiourea (TU) was synthesized and dried over $\mathrm{CaH}_{2}$ in dry THF as previously reported. ${ }^{1}(+)-$ Sparteine (SP) was distilled over $\mathrm{CaH}_{2}$ prior to use. Other chemicals and solvents were purchased from either of the distributors mentioned above and used as received unless specifically described.

Measurements. ${ }^{1} \mathrm{H}$ NMR spectra were measured on a JEOL $400 \mathrm{MHz}$ JNM-ECX spectrometer or a JEOL 500MHz JNM-ECX spectrometer. Size exclusion chromatography (SEC) was performed using a Tosoh integrated GPC system HLC-8220 GPC equipped with a pump, column oven, degasser, autosampler, detectors using refractive index (RI) and UV, serially connected columns of TSK-gels super AW5000, super AW4000, and super AW3000 (Tosoh). THF was used as eluent with a flow rate of $1.0 \mathrm{~mL} \min ^{-1}$ at $40{ }^{\circ} \mathrm{C}$. Molecular weights and their distribution were calculated from a calibration curve that was obtained from elution time of polystyrene standards with different molecular weights $\left(M_{\mathrm{n}}\right.$ $=2500,5870,9490,17100,37200,98900,189000,397000,707000,1110000)$. 
Synthesis of PEG-UBA-OH (3). A macroinitiator comprising PEG and UBA structure was synthesized by following a protocol in the previous report by Kim et al. ${ }^{2}$ with a slight modification. Briefly, $p$ xylylenediamine $(20.4 \mathrm{~g}, 0.15 \mathrm{~mol})$ and TBD $(0.7 \mathrm{~g}, 0.05 \mathrm{~mol})$ were added in toluene $(100 \mathrm{~mL})$ and heated at $80{ }^{\circ} \mathrm{C}$. A toluene solution $(100 \mathrm{~mL})$ of methyl 4-(hydroxymethyl)benzoate $(8.3 \mathrm{~g}, 0.05 \mathrm{~mol})$ was added dropwise into the mixture and stirred at $110^{\circ} \mathrm{C}$ overnight. Precipitates formed were filtered, washed with toluene $(100 \mathrm{~mL})$, DCM $(100 \mathrm{~mL})$, and diethyl ether $(100 \mathrm{~mL})$, and dried in vacuum at room temperature overnight. The residue was then recrystallized from 2-propanol, followed by methanol to form white crystals as $N$-(4-aminomethylbenzyl)-4-hydroxymethylbenzamide $(\mathbf{4} ; 4.8 \mathrm{~g}, 35 \%) .{ }^{1} \mathrm{H}$ NMR (400 MHz, DMSO- $\left.d_{6}, \delta\right): 3.68$ (s, 2H; $\left.\underline{\mathrm{C}}_{2}-\mathrm{NH}_{2}\right), 4.44$ (d, $\left.J=6.3 \mathrm{~Hz}, 2 \mathrm{H} ; \mathrm{C}_{2}-\mathrm{NHCO}\right), 4.55$ (s, 2H; $\left.\underline{\mathrm{C}}_{2}-\mathrm{OH}\right), 5.30(\mathrm{~s}, 1 \mathrm{H} ; \mathrm{O} \underline{\mathrm{H}}), 7.19-7.30(\mathrm{~m}, 4 \mathrm{H} ; \mathrm{Ar}-\underline{\mathrm{H}}), 7.40$ (d, $\left.J=8.2 \mathrm{~Hz}, 2 \mathrm{H} ; \mathrm{Ar}-\underline{\mathrm{H}}\right), 7.85$ (d, $J=$ $7.7 \mathrm{~Hz}, 2 \mathrm{H} ; \mathrm{Ar}-\underline{\mathrm{H}}), 8.97$ (t, $J=5.7 \mathrm{~Hz}, 1 \mathrm{H} ; \mathrm{CON} \underline{\mathrm{H}})$.

PEG-NH $2\left(1.0 \mathrm{~g},\left[\mathrm{NH}_{2}\right]=0.2 \mathrm{mmol}\right)$ preliminarily dried at $50{ }^{\circ} \mathrm{C}$ for 1 hour was dissolved in dry DMF (5 ml), added dropwise into a dry DMF solution ( $5 \mathrm{~mL})$ of PFC (0.1 g, $0.25 \mathrm{mmol})$, and stirred for 1 hour. Then, a dry DMF solution $(5 \mathrm{~mL})$ of $4(0.081 \mathrm{~g}, 0.3 \mathrm{mmol})$ preliminarily dissolved at $60{ }^{\circ} \mathrm{C}$ was added gradually into the mixture described above and stirred at room temperature overnight. The reaction mixture was concentrated and precipitated in diethyl ether $(90 \mathrm{~mL})$. The precipitates were dissolved in DCM, which were passed through a syringe filter ( $0.2 \mu \mathrm{m}$ sized pores; PTFE). The filtrate was dried under reduced pressure, and the residue was dissolved in dry THF to dehydrate over $\mathrm{CaH}_{2}$. After removing $\mathrm{CaH}_{2}$ by a syringe filter $(0.2 \mu \mathrm{m}$ sized pores; PTFE), the filtrate was evaporated and dried in vacuo to form a white solid as a macroinitiator $\mathbf{3}$, which was stored in a nitrogen-filled glove box $(0.77 \mathrm{~g}, 73 \%) .{ }^{1} \mathrm{H}-\mathrm{NMR}\left(500 \mathrm{MHz}, \mathrm{DMSO}-d_{6}, \delta\right): 3.15$ (m, 2H; 5), $3.24(\mathrm{~s}, 3 \mathrm{H} ; 1), 3.39-3.76(\mathrm{~m}$, $649 \mathrm{H} ; 2,3$, and 4), $4.17(\mathrm{~d}, J=6.2 \mathrm{~Hz}, 2 \mathrm{H} ; 8), 4.44(\mathrm{~d}, J=5.7 \mathrm{~Hz}, 2 \mathrm{H} ; 11), 4.55(\mathrm{~d}, J=5.7 \mathrm{~Hz}, 2 \mathrm{H} ; 15)$, $5.30(\mathrm{t}, J=5.7 \mathrm{~Hz}, 1 \mathrm{H} ; 16), 5.95(\mathrm{t}, J=5.7 \mathrm{~Hz}, 1 \mathrm{H} ; 6), 6.38(\mathrm{dd}, J=5.7,11.9 \mathrm{~Hz} 1 \mathrm{H} ; 7), 7.19(\mathrm{~d}, J=7.9$ 
$\mathrm{Hz}, 2 \mathrm{H} ; 9), 7.25(\mathrm{~d}, J=7.9 \mathrm{~Hz}, 2 \mathrm{H} ; 12), 7.39(\mathrm{~d}, J=8.5 \mathrm{~Hz}, 2 \mathrm{H} ; 14), 7.85(\mathrm{~d}, J=8.5 \mathrm{~Hz}, 2 \mathrm{H} ; 13), 8.96$ $(\mathrm{t}, J=5.7 \mathrm{~Hz}, 1 \mathrm{H} ; 12)$.

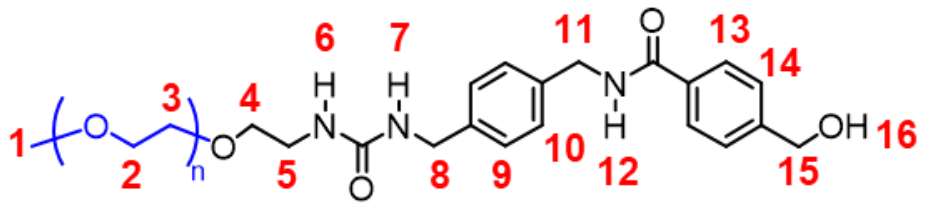

Synthesis of PEG-UBA-PLLA (1a). A representative binary catalyst system of thiourea (TU) and (+)sparteine (SP) was used for ring-opening polymerization (ROP) of L-lactide. ${ }^{1,3}$ In a nitrogen-filled glove box, which keeps the dew point below $-90{ }^{\circ} \mathrm{C}, 3(0.250 \mathrm{~g}, 0.047 \mathrm{mmol}), \mathrm{TU}(0.017 \mathrm{~g}, 0.047 \mathrm{mmol})$, and SP $(0.005 \mathrm{~g}, 0.024 \mathrm{mmol})$ were dissolved in dry DCM $(2.2 \mathrm{~mL})$ and added to a vial that LLA $(0.24 \mathrm{~g}$, $1.65 \mathrm{mmol}$ ) was placed. After stirring at room temperature for $9 \mathrm{~h}$, at which full monomer conversion was confirmed by ${ }^{1} \mathrm{H}$ NMR, the polymerization was quenched by benzoic acid $(0.029 \mathrm{~g}, 0.24 \mathrm{mmol})$. The mixture was then precipitated in diethyl ether $(40 \mathrm{~mL})$, and the precipitates was filtered to obtain a white solid as PEG-UBA-PLLA (1a; $0.44 \mathrm{~g}, 83 \%) .{ }^{1} \mathrm{H}$ NMR (500 MHz, DMSO- $\left.d_{6}, \delta\right): 1.29(\mathrm{~d}, J=6.8$ $\mathrm{Hz}, 3 \mathrm{H} ; 18), 1.35-1.67$ (m, 230H; 16), 3.15 (m, 2H; 5), 3.24 (s, 3H; 1), 3.38-3.72 (m, 528H; 2, 3, and 4), $4.17(\mathrm{~d}, J=6.2 \mathrm{~Hz}, 2 \mathrm{H} ; 8), 4.21(\mathrm{q}, J=6.2 \mathrm{~Hz}, 1 \mathrm{H} ; 19), 4.44(\mathrm{~d}, J=5.7 \mathrm{~Hz}, 2 \mathrm{H} ; 11), 5.05-5.25(\mathrm{~m}$, $78 \mathrm{H} ; 15,17), 5.47(\mathrm{~d}, J=5.1 \mathrm{~Hz}, 1 \mathrm{H} ; 20), 5.95(\mathrm{dd}, \mathrm{J}=5.7,11.9 \mathrm{~Hz}, 1 \mathrm{H} ; 6), 6.38(\mathrm{dd}, J=5.1,11.3 \mathrm{~Hz}$, $1 \mathrm{H} ; 7), 7.19(\mathrm{~d}, J=7.9 \mathrm{~Hz}, 2 \mathrm{H} ; 9), 7.25(\mathrm{~d}, J=7.9 \mathrm{~Hz}, 2 \mathrm{H} ; 10), 7.44(\mathrm{~d}, J=8.5 \mathrm{~Hz}, 2 \mathrm{H} ; 14), 7.89(\mathrm{~d}, J=$ $8.5 \mathrm{~Hz}, 2 \mathrm{H} ; 13), 9.03(\mathrm{t}, J=6.2 \mathrm{~Hz}, 1 \mathrm{H} ; 12)$. SEC (THF, $\left.40{ }^{\circ} \mathrm{C}\right): M_{\mathrm{n}} 9.2 \times 10^{3} \mathrm{~g} \mathrm{~mol}^{-1}, \bigoplus_{\mathrm{M}} 1.19$. DP (NMR): PLLA $=38$

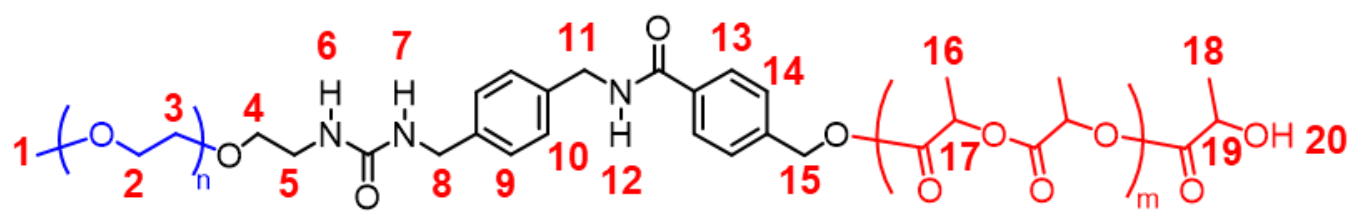


Synthesis of PEG-UBA-PDLLA (1a-R). The reaction was carried out in the same way described above for 1a, using a mixture of LLA $(0.125 \mathrm{~g}, 0.87 \mathrm{mmol})$ and DLA $(0.125 \mathrm{~g}, 0.87 \mathrm{mmol})$ as monomers instead. PEG-UBA-PDLLA (1a-R) was obtained as a white solid (0.24 g, $47 \%) .{ }^{1} \mathrm{H}-\mathrm{NMR}(500 \mathrm{MHz}$, DMSO- $\left.d_{6}, \delta\right): 1.27$ (d, $\left.J=6.2 \mathrm{~Hz}, 3 \mathrm{H}, 18\right), 1.35-1.67$ (m, 219H, 16), 3.15 (m, 2H, 5), 3.24 (s, 3H, 1), $3.38-3.72(\mathrm{~m}, 507 \mathrm{H}, 2,3$, and 4), $4.17(\mathrm{~d}, J=5.7 \mathrm{~Hz}, 2 \mathrm{H}, 8), 4.18-4.24(\mathrm{~m}, 1 \mathrm{H}, 19), 4.44(\mathrm{~m}, 2 \mathrm{H}, 11)$, 5.05-5.25 (m, 75H, 17), $5.47(\mathrm{~d}, J=5.7 \mathrm{~Hz}, 1 \mathrm{H}, 20), 5.95(\mathrm{~m}, 1 \mathrm{H}, 6), 6.38(\mathrm{~m}, 1 \mathrm{H}, 7), 7.19(\mathrm{~d}, J=7.9$ $\mathrm{Hz}, 2 \mathrm{H}, 9), 7.25(\mathrm{~d}, J=7.9 \mathrm{~Hz}, 2 \mathrm{H}, 10), 7.44(\mathrm{~d}, J=7.9 \mathrm{~Hz}, 2 \mathrm{H}, 14), 7.89(\mathrm{~d}, J=7.4 \mathrm{~Hz}, 2 \mathrm{H}, 13), 9.03$ (m, 1H, 12). SEC (THF, $\left.40^{\circ} \mathrm{C}\right): M_{\mathrm{n}} 16.8 \times 10^{3} \mathrm{~g} \mathrm{~mol}^{-1}, \bigoplus_{\mathrm{M}} 1.08 . \mathrm{DP}(\mathrm{NMR}):$ PDLLA $=37$

Synthesis of PEG-UBA-PCL (1b). Diphenyl phosphate (DPP) was employed for the ROP of CL and TMC. ${ }^{4,5}$ These were used instead of 1,8-diazabicyclo[5.4.0]undec-7-ene (DBU) and TBD, which are often used for the ROP of CL and TMC,${ }^{6,7}$ to avoid the possibility of deprotonation of urea and amide in UBA by these strong bases. ${ }^{8}$ In a nitrogen-filled glove box, $3(0.370 \mathrm{~g}, 0.07 \mathrm{mmol})$, and DPP $(0.017 \mathrm{~g}$, $0.07 \mathrm{mmol})$ were dissolved in dry DCM $(2.1 \mathrm{~mL})$ and added to a vial that CL $(0.359 \mathrm{~g}, 3.15 \mathrm{mmol})$ was placed. After stirring at room temperature for $49 \mathrm{~h}$, at which full monomer conversion was confirmed by ${ }^{1} \mathrm{H}$ NMR, the polymerization was quenched by triethylamine. The mixture was then precipitated in diethyl ether $(30 \mathrm{~mL})$, followed by a 1:1 mixed solution of methanol and hexane $(50 \mathrm{~mL})$ to form a pale yellowish solid as $\mathbf{1 b}(0.312 \mathrm{~g}, 43 \%) .{ }^{1} \mathrm{H}$ NMR (500 MHz, DMSO- $\left.d_{6}, \delta\right): 1.19-1.36(\mathrm{~m}, 93 \mathrm{H} ; 18), 1.37$ (m, 2H; 23), 1.44-1.63 (m, 177H; 17 and 19), 2.27 (t, $J=7.4 \mathrm{~Hz}, 89 \mathrm{H} ; 16), 3.15$ (m, 2H; 5), 3.24 (s, 3H; 1), 3.38-3.72 (m, 587H; 2, 3, 4, and water), 3.98 (t, $J=6.8 \mathrm{~Hz}, 88 \mathrm{H} ; 20), 4.17(\mathrm{~d}, J=6.2 \mathrm{~Hz}, 2 \mathrm{H} ; 8)$, $4.33(\mathrm{t}, J=5.1 \mathrm{~Hz}, 1 \mathrm{H} ; 26), 4.44(\mathrm{~d}, J=6.2 \mathrm{~Hz}, 2 \mathrm{H} ; 11), 5.13(\mathrm{~s}, 2 \mathrm{H} ; 15), 5.95(\mathrm{~m}, 1 \mathrm{H} ; 6), 6.38(\mathrm{~m}, 1 \mathrm{H}$; 7), $7.18(\mathrm{~d}, J=7.9 \mathrm{~Hz}, 2 \mathrm{H} ; 9), 7.25(\mathrm{~d}, J=8.5 \mathrm{~Hz}, 2 \mathrm{H} ; 10), 7.44(\mathrm{~d}, J=8.5 \mathrm{~Hz}, 2 \mathrm{H} ; 14), 7.89$ (d, $J=7.9$ 
$\mathrm{Hz}, 2 \mathrm{H} ; 13), 9.00(\mathrm{t}, J=5.7 \mathrm{~Hz}, 1 \mathrm{H} ; 12)$. SEC (THF, $\left.40{ }^{\circ} \mathrm{C}\right): M_{\mathrm{n}} 10.7 \times 10^{3} \mathrm{~g} \mathrm{~mol}^{-1}, \bigoplus_{\mathrm{M}} 1.11 . \mathrm{DP}$ (NMR): $\mathrm{PCL}=45$

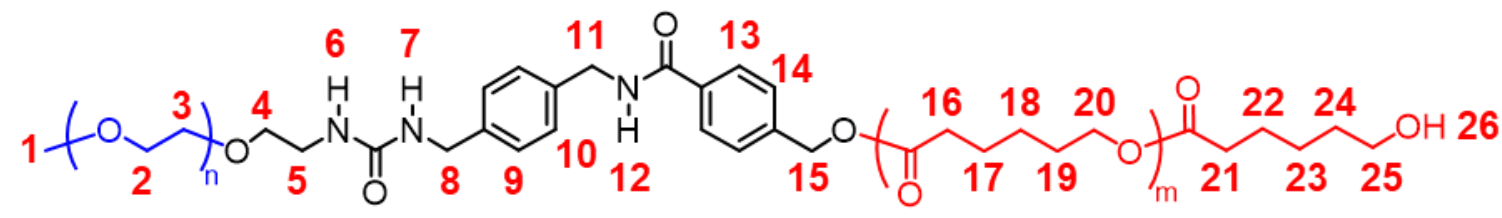

Synthesis of PEG-UBA-PTMC (1c). The reaction was carried out in the same way described above, using TMC (0.35 g, $3.4 \mathrm{mmol})$ as a monomer instead and stirring for 1 week. PEG-UBA-PTMC (1c) was obtained as a white solid $(0.545 \mathrm{~g}, 78 \%) .{ }^{1} \mathrm{H}$ NMR $\left(500 \mathrm{MHz}\right.$, DMSO- $d_{6}, \delta$ ): 1.72 (quint, $J=6.2 \mathrm{~Hz}$, 2H; 20), 1.94 (quint, $J=6.4 \mathrm{~Hz}, 97 \mathrm{H} ; 17), 3.15$ (m, 2H; 5), 3.24 (s, 3H; 1), 3.38-3.72 (m, 446H; 2, 3 , and 4), 3.98 (t, $J=6.2 \mathrm{~Hz}, 2 \mathrm{H} ; 21), 4.13(\mathrm{t}, J=6.2 \mathrm{~Hz}, 199 \mathrm{H} ; 16$ and 18), 4.28 (t, $J=6.0 \mathrm{~Hz}, 2 \mathrm{H} ; 26)$, $4.44(\mathrm{~d}, J=5.7 \mathrm{~Hz}, 2 \mathrm{H} ; 11), 4.54(\mathrm{t}, J=5.1 \mathrm{~Hz}, 1 \mathrm{H} ; 22), 5.18(\mathrm{~s}, 2 \mathrm{H} ; 15), 5.95(\mathrm{t}, J=6.0 \mathrm{~Hz}, 1 \mathrm{H} ; 6)$, $6.38(\mathrm{t}, J=6.0 \mathrm{~Hz}, 1 \mathrm{H} ; 7), 7.18(\mathrm{~d}, \mathrm{~J}=8.5 \mathrm{~Hz}, 2 \mathrm{H} ; 9), 7.25(\mathrm{~d}, J=7.9 \mathrm{~Hz}, 2 \mathrm{H} ; 12), 7.46(\mathrm{~d}, J=8.5 \mathrm{~Hz}$, $2 \mathrm{H} ; 14), 7.89(\mathrm{~d}, J=8.5 \mathrm{~Hz}, 2 \mathrm{H} ; 13), 9.03(\mathrm{t}, J=6.2 \mathrm{~Hz}, 1 \mathrm{H} ; 15)$. SEC (THF, $\left.40{ }^{\circ} \mathrm{C}\right): M_{\mathrm{n}} 9.4 \times 10^{3} \mathrm{~g}$ $\mathrm{mol}^{-1}, \bigoplus_{\mathrm{M}} 1.11 . \mathrm{DP}(\mathrm{NMR}): \mathrm{PTMC}=50$

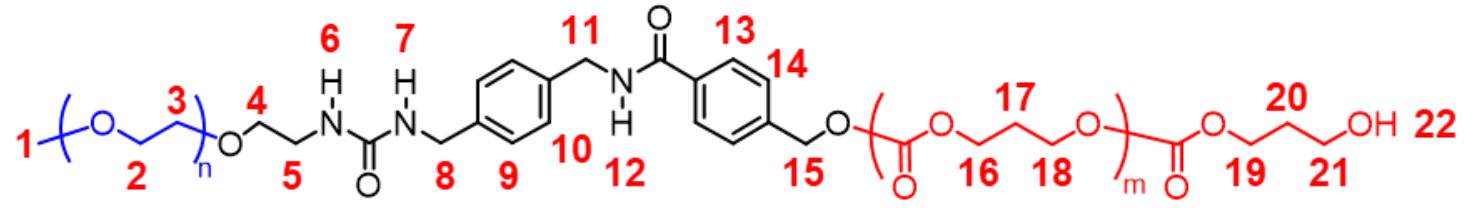

Synthesis of PEG-b-PLLA (2a). The reaction was carried out in the same way as described above for 1a, using LLA (0.300 g, $2.08 \mathrm{mmol})$, TU (0.022g, $0.06 \mathrm{mmol}), \mathrm{SP}(0.007 \mathrm{~g}, 0.03 \mathrm{mmol})$, and mPEG-OH $(0.300 \mathrm{~g}, 0.06 \mathrm{mmol})$ as an initiator instead. PEG- $b$-PLLA (2a) was obtained as a white solid $(0.28 \mathrm{~g}$, 47\%). ${ }^{1} \mathrm{H}$ NMR (500 MHz, DMSO- $\left.d_{6}, \delta\right): 1.28$ (d, $\left.J=7.4 \mathrm{~Hz}, 3 \mathrm{H} ; 8\right), 1.37-1.53$ (m, 202H; 7), 3.24 (s, 
3H; 1), 3.34-3.67 (m, 460H; 2, 3, and 4), 4.13-4.26 (m, 3H; 5 and 9), 5.16-5.27 (m, 67H; 6). SEC (THF, $\left.40{ }^{\circ} \mathrm{C}\right): M_{\mathrm{n}} 10.2 \times 10^{3} \mathrm{~g} \mathrm{~mol}^{-1}, \bigoplus_{\mathrm{M}} 1.08$. DP (NMR): PLLA $=34$

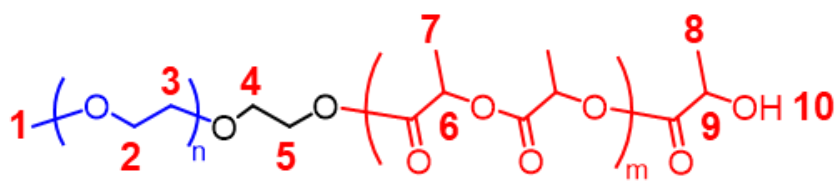

Synthesis of PEG-b-PDLLA (2a-R). The reaction was carried out in the same way as described above for 2a, using LLA $(0.150 \mathrm{~g}, 1.04 \mathrm{mmol})$ and DLA $(0.150 \mathrm{~g}, 1.04 \mathrm{mmol})$ as monomers instead. PEG- $b$ PDLLA (2a-R) was obtained as a white solid (0.305 g, $50 \%) .{ }^{1} \mathrm{H}-\mathrm{NMR}\left(500 \mathrm{MHz}\right.$, DMSO- $\left.d_{6}, \delta\right): 1.28$ (d, $J=7.4 \mathrm{~Hz}, 8), 1.37-1.53$ (m, 211H, 7), 3.24 (s, 3H, 1), 3.38-3.66 (m, 498H, 2, 3, and 4), 4.14-4.26 (m, 3H, 5 and 9), 5.08-5.26 (m, 69H, 6). SEC (THF, $40^{\circ} \mathrm{C}$ ): $M_{\mathrm{n}} 14.1 \times 10^{3} \mathrm{~g} \mathrm{~mol}^{-1}, \bigoplus_{\mathrm{M}} 1.04$. DP (NMR): PDLLA $=35$

Synthesis of PEG-b-PCL (2b). The reaction was carried out in the same way as described above for $\mathbf{1 b}$, using CL (0.500 g, $4.38 \mathrm{mmol})$, DPP (0.024g, $0.097 \mathrm{mmol})$, and mPEG-OH (0.485 g, $0.097 \mathrm{mmol})$ as an initiator instead. PEG-b-PCL (2b) was obtained as a white solid (0.87 g, 88\%). ${ }^{1} \mathrm{H}$ NMR (500 MHz, DMSO- $\left.d_{6}, \delta\right): 1.20-1.34(\mathrm{~m}, 88 \mathrm{H} ; 8), 1.34-1.44(\mathrm{~m}, 2 \mathrm{H} ; 13), 1.44-1.61(\mathrm{~m}, 174 \mathrm{H} ; 7,9,12$, and 14), $2.27(\mathrm{t}, J=7.4 \mathrm{~Hz}, 90 \mathrm{H} ; 6$ and 11), $3.24(\mathrm{~s}, 3 \mathrm{H} ; 1), 3.38-3.67(\mathrm{~m}, 483 \mathrm{H} ; 2,3$ and 4), $3.98(\mathrm{t}, J=6.2 \mathrm{~Hz}$, $85 \mathrm{H} ; 10), 4.11(\mathrm{t}, J=4.8 \mathrm{~Hz}, 2 \mathrm{H} ; 5), 4.33(\mathrm{t}, J=4.8 \mathrm{~Hz}, 1 \mathrm{H} ; 16)$. SEC (THF, $\left.40{ }^{\circ} \mathrm{C}\right): M_{\mathrm{n}} 10.4 \times 10^{3} \mathrm{~g}$ $\mathrm{mol}^{-1}, \bigoplus_{\mathrm{M}}$ 1.09. DP (NMR): $\mathrm{PCL}=44$

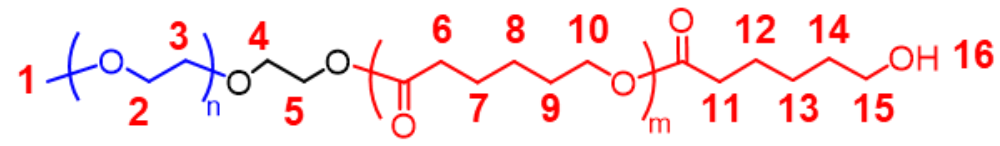


Synthesis of PEG-b-PTMC (2c). The reaction was carried out in the same way as described above for 1c, using TMC (0.300 g, $3.0 \mathrm{mmol})$, DPP (0.015 g, $0.06 \mathrm{mmol})$, and mPEG-OH $(0.300 \mathrm{~g}, 0.06 \mathrm{mmol})$ as an initiator instead. PEG- $b$-PTMC (2c) was obtained as a white solid $(0.45 \mathrm{~g}, 75 \%) .{ }^{1} \mathrm{H}$ NMR $(500 \mathrm{MHz}$, DMSO- $\left.d_{6}, \delta\right): 1.20-1.34(\mathrm{~m}, 2 \mathrm{H} ; 10), 1.87-2.00(\mathrm{~m}, 96 \mathrm{H} ; 7), 3.23(\mathrm{~s}, 3 \mathrm{H} ; 1), 3.38-3.73(\mathrm{~m}, 503 \mathrm{H} ; 2,3$, and 4), 3.90-3.99 (m, 2H; 11), $4.13(\mathrm{t}, J=6.3 \mathrm{~Hz}, 200 \mathrm{H} ; 6,8$, and 9), 4.27-4.34 (m, 2H; 5), 4.51-4.57 $(\mathrm{m}, 1 \mathrm{H} ; 12) . \mathrm{SEC}\left(\mathrm{THF}, 40{ }^{\circ} \mathrm{C}\right): M_{\mathrm{n}} 9.2 \times 10^{3} \mathrm{~g} \mathrm{~mol}^{-1}, D_{\mathrm{M}} 1.07 . \mathrm{DP}(\mathrm{NMR}): \mathrm{PTMC}=49$

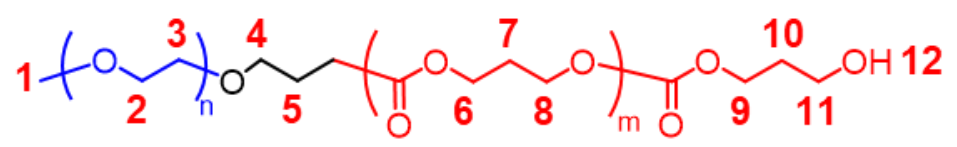



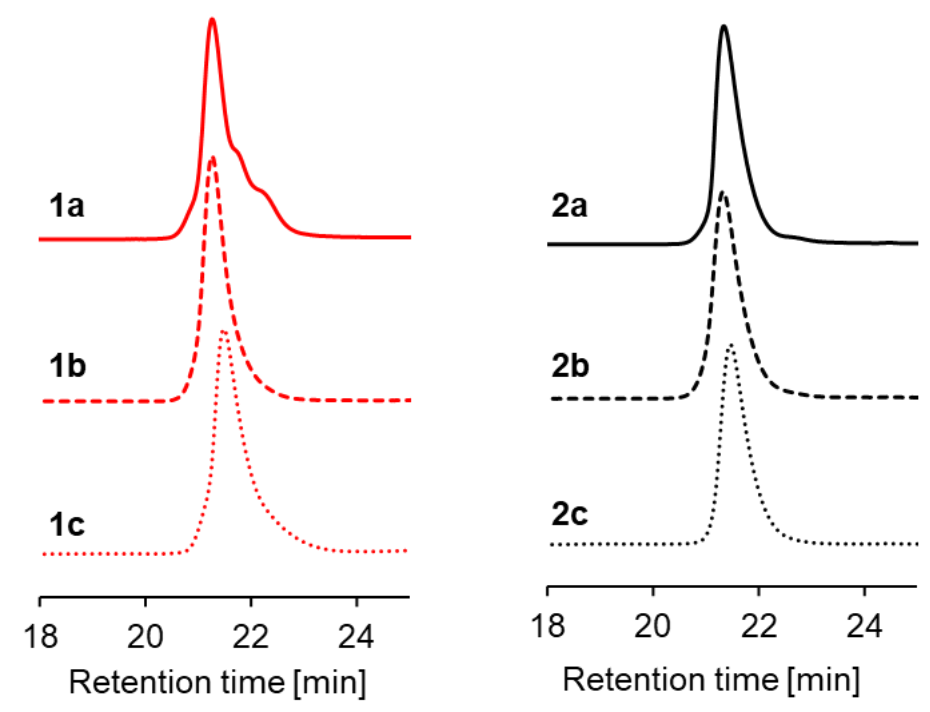

Figure S1. SEC charts of the PEGylated block copolymers measured at $40{ }^{\circ} \mathrm{C}$ using THF as an eluent. Polystyrene standards were used for calibration.

Morphology observation of the assemblies by transmission electron microscopy (TEM). The water dispersion of the block copolymers was mixed with phosphotungstic acid (PTA) to formulate $0.2 \mathrm{w} / \mathrm{v} \%$ of PTA-containing solution, incubating for $1 \mathrm{~h}$. The stained dispersion was deposited onto a 250 mesh copper grid with a carbon substrate, leaving for $5 \mathrm{~min}$. The residual solution was removed by a filter paper, and the specimens were dried under ambient conditions overnight and in vacuum for another $1 \mathrm{~h}$. The observation was performed using a JEOL JEM-2100 (JEOL, Tokyo, Japan) with an acceleration voltage of $200 \mathrm{keV}$. 

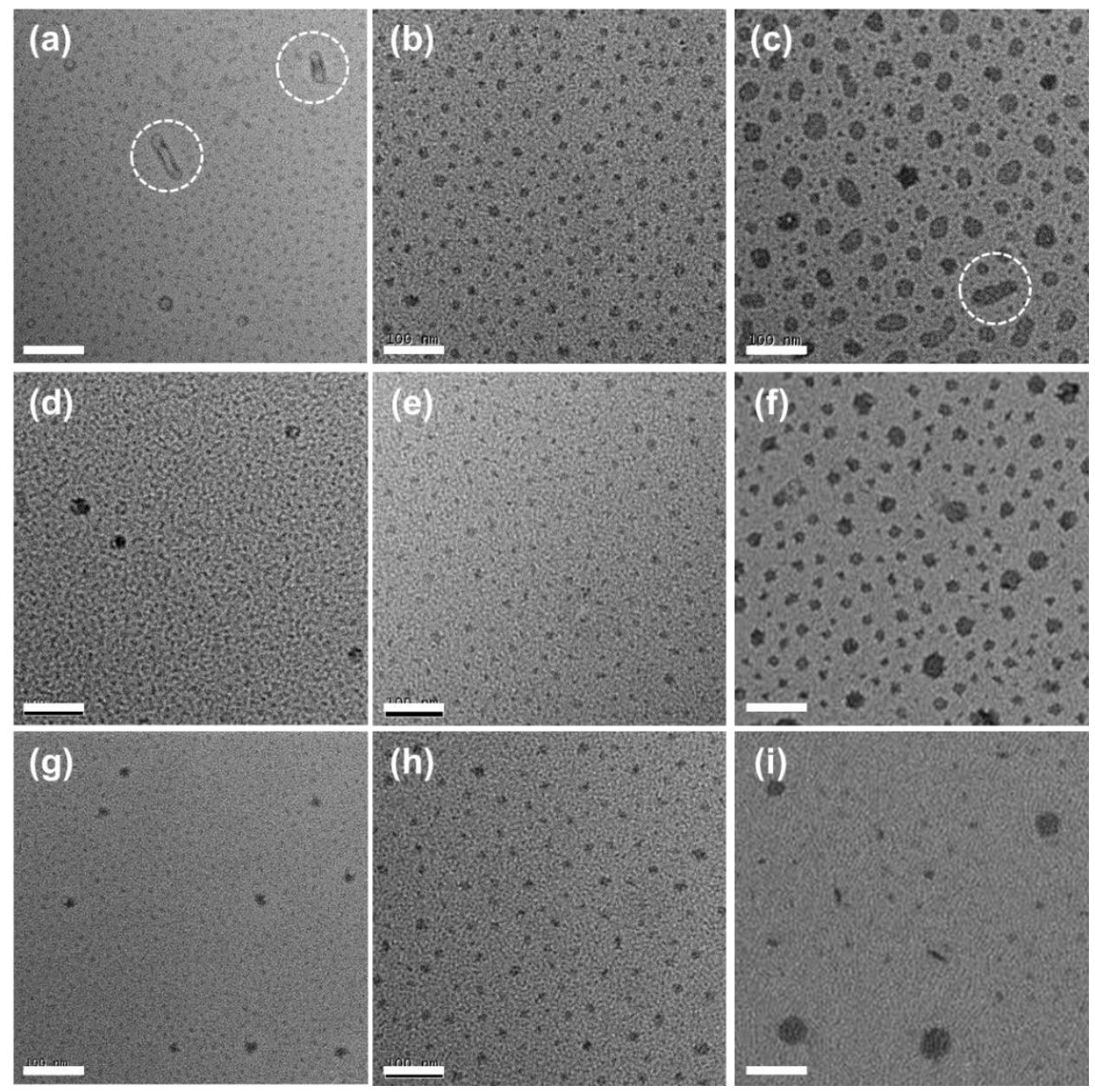

Figure S2. Representative TEM images of the block copolymer assemblies prepared by membrane dialysis: (a-f) day 0, (g-i) day 7-11 stored at $4{ }^{\circ} \mathrm{C}$. (a) 1a, (b) 1b, (c) 1c, (d, g) 2a, (e, h) 2b, and (f, i) $\mathbf{2 c}$. Dotted circles indicate non-spherical assemblies. Bar scales are $100 \mathrm{~nm}$. 

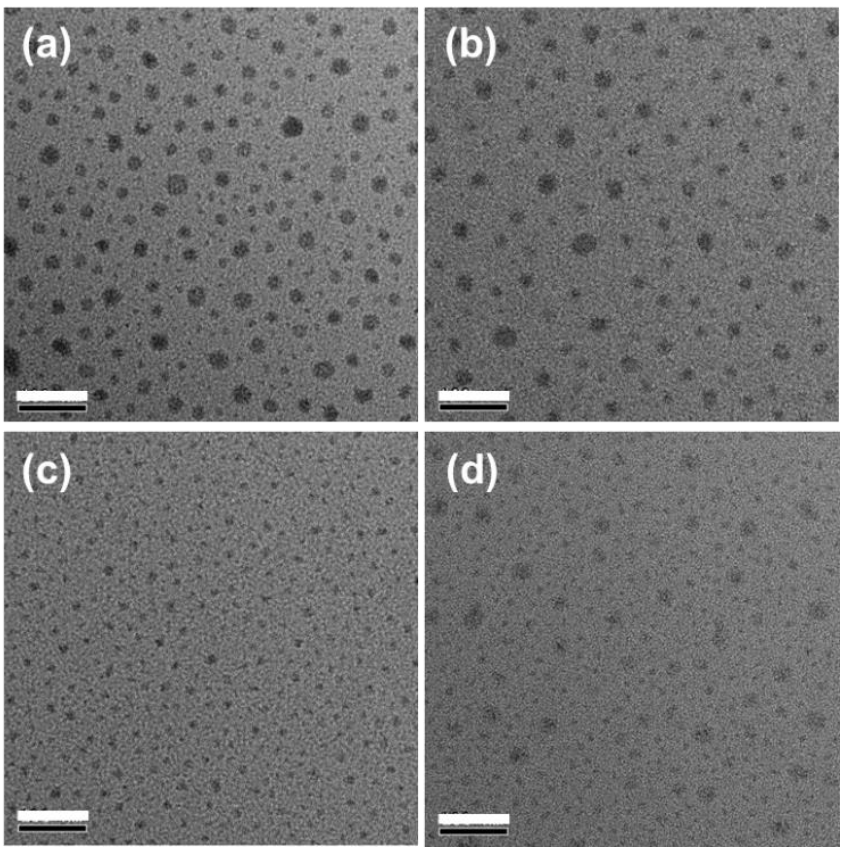

Figure S3. Representative TEM images of the block copolymer assemblies prepared by membrane dialysis: (a, c) day 0, (b, d) day 8-9 stored at $4{ }^{\circ} \mathrm{C}$. (a, b) 1a-R, and (c, d) 2a-R. Bar scales are $100 \mathrm{~nm}$.

Particle size distribution analysis by dynamic light scattering (DLS). The water dispersion of block copolymers ( $200 \mu \mathrm{L})$ was placed in a quartz cuvette. The measurement was operated using ZETA SIZER Nano ZS (Malvern Instruments) at $25{ }^{\circ} \mathrm{C}$. Particle sizes and size distributions were obtained from scattering intensities triplicated and averaged. 

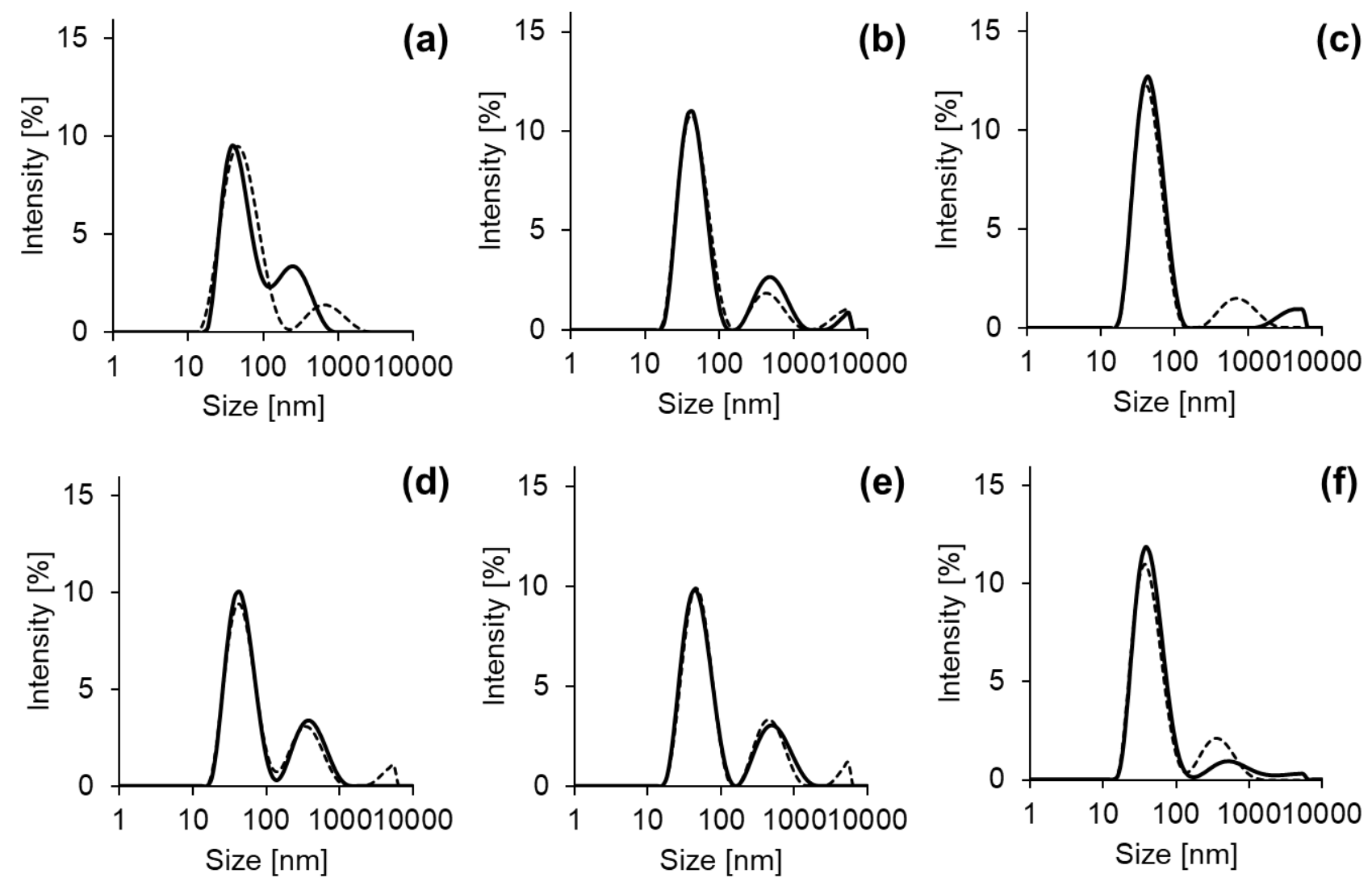

Figure S4. Scattering intensity-averaged particle size distributions of the block copolymer assemblies in water obtained by DLS: (a) 1a, (b) 1b, (c) 1c, (d) 2a, (e) 2b, and (f) 2c. Dotted lines: day 0, solid lines: day 14 stored at $4{ }^{\circ} \mathrm{C}$. Polymer dispersions were prepared by membrane dialysis and formulated to 0.1 $\mathrm{w} / \mathrm{v} \%$.

Thermal properties of block copolymers in bulk. Block copolymers after precipitation were used for evaluation of their thermal properties by differential scanning calorimetry (DSC). The measurement was performed using a Hitachi High-Tech Science X-DSC7000 calorimeter with a ramp of $5^{\circ} \mathrm{C} \min ^{-1}$ under a nitrogen atmosphere. Three to five $\mathrm{mg}$ of the specimens loaded in an aluminum pan were heated from room temperature to the predetermined temperature, cooled to $-50{ }^{\circ} \mathrm{C}$, and heated again. The first cooling scans and the second heating scans were used for the evaluation of the thermal properties of the block copolymers. The onset temperature was adopted as the transition temperature. 

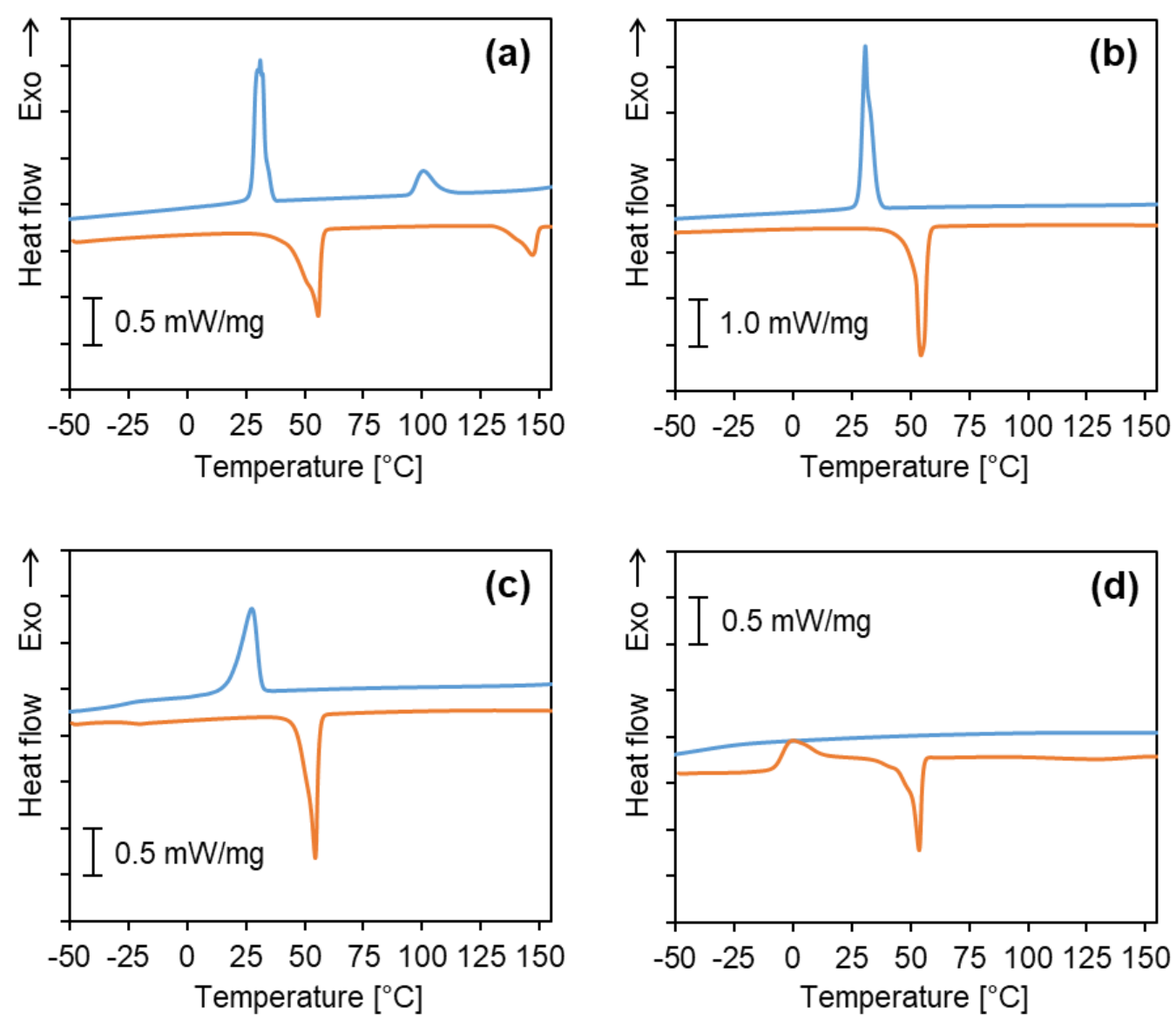

Figure S5. DSC thermograms of the UBA-containing block copolymers: (a) 1a, (b) 1b, (c) 1c, and (d) 1a-R. Blue lines: 1st cooling scans, orange lines: 2nd heating scans. The cooling and heating rates are $5^{\circ} \mathrm{C} \min ^{-1}$.

As shown in Figure S5, PLLA-conjugated block copolymer 1a indicated two peaks on both heating and cooling scans, corresponding to melting and crystallization of PEG and PLLA segments. PCL-conjugated block copolymer 1b showed single peaks on the heating and cooling scans, which are considered as a result of concomitant melting and crystallization of PEG and PCL segments whose melting points appear in similar temperature ranges $\left(50-60^{\circ} \mathrm{C}\right)$. In addition, the heat of fusion for $\mathbf{1 b}$ $(\sim 195 \mathrm{~mJ} / \mathrm{mg})$ is much higher than those of 1a and 1c $(\sim 99 \mathrm{~mJ} / \mathrm{mg})$, supporting it as a summation of melting of PEG and PCL. The UBA-containing block copolymers with amorphous hydrophobic 
segments, 1c and 1a-R, exhibited only melting and crystallization of PEG, although crystallization behaviors of the PEG segments are different between these two polymers. These results suggest that hydrophobic blocks of $\mathbf{1 a}$ and $\mathbf{1 b}$ can serve as semi-crystalline segments for the self-assembly in an aqueous environment.

All-atom molecular dynamics (MD) simulation. We performed an all-atom MD simulation with GROMACS 4.6.7 to investigate the assemble structure of 1a in water using an analog comprising a 10mer of PEG, UBA, and 10-mer of PLLA, namely PEG $_{10}-\mathrm{UBA}^{-P_{L L A}}{ }_{10}$. The partial atomic charges were calculated using the restraint electrostatic potential (RESP) ${ }^{9}$ methodology based on the DFT calculations (B3LYP/6-31g(d)) with GAUSSIAN 09 program. ${ }^{10}$ For calculating the intra- and intermolecular interactions, the generalized Amber force field ${ }^{11}$ and TIP3P parameters were used for PEG $_{10}$-UBAPLLA $_{10}$ and water molecules, respectively. Initially, the lamellar structure formed by 30 molecules of PEG $_{10}$-UBA-PLLA 10 , in which the hydrophobic PLLA groups were interdigitated each other were placed in the center of the simulation box of $(x, y, z)=(24,10,6) \mathrm{nm}$ (Figure S6). The preliminary MD simulation suggested that the lamellar system without interdigitated hydrophobic chains was expected to take a long time to reach equilibrium. Its surrounding empty space in the simulation box were filled with 45,236 water molecules. After the steepest descent energy minimization, the equilibration run was performed at 1 bar and $300 \mathrm{~K}$ for $10 \mathrm{~ns}$ under the periodic boundary conditions. The temperature and pressure of the system were maintained using the velocity rescaling thermostat ${ }^{12}$ with the relaxation time of $0.2 \mathrm{ps}$ and the Berendsen barostat ${ }^{13}$ with the relaxation time of $2.0 \mathrm{ps}$ and the compressibility of $4.5 \times$ $10^{-5} \mathrm{bar}^{-1}$, respectively. All bonds connected to hydrogen atoms of the molecules were constrained with the LINCS ${ }^{14}$ algorithm and the time step was set to $2 \mathrm{fs}$. The electrostatic interactions were calculated 
using the smooth particle-mesh Ewald (PME) ${ }^{15}$ method with the real space cutoff of $1.4 \mathrm{~nm}$ and the grid spacing of $0.30 \mathrm{~nm}$. The van der Waals interactions were calculated with the cutoff of $1.4 \mathrm{~nm}$.
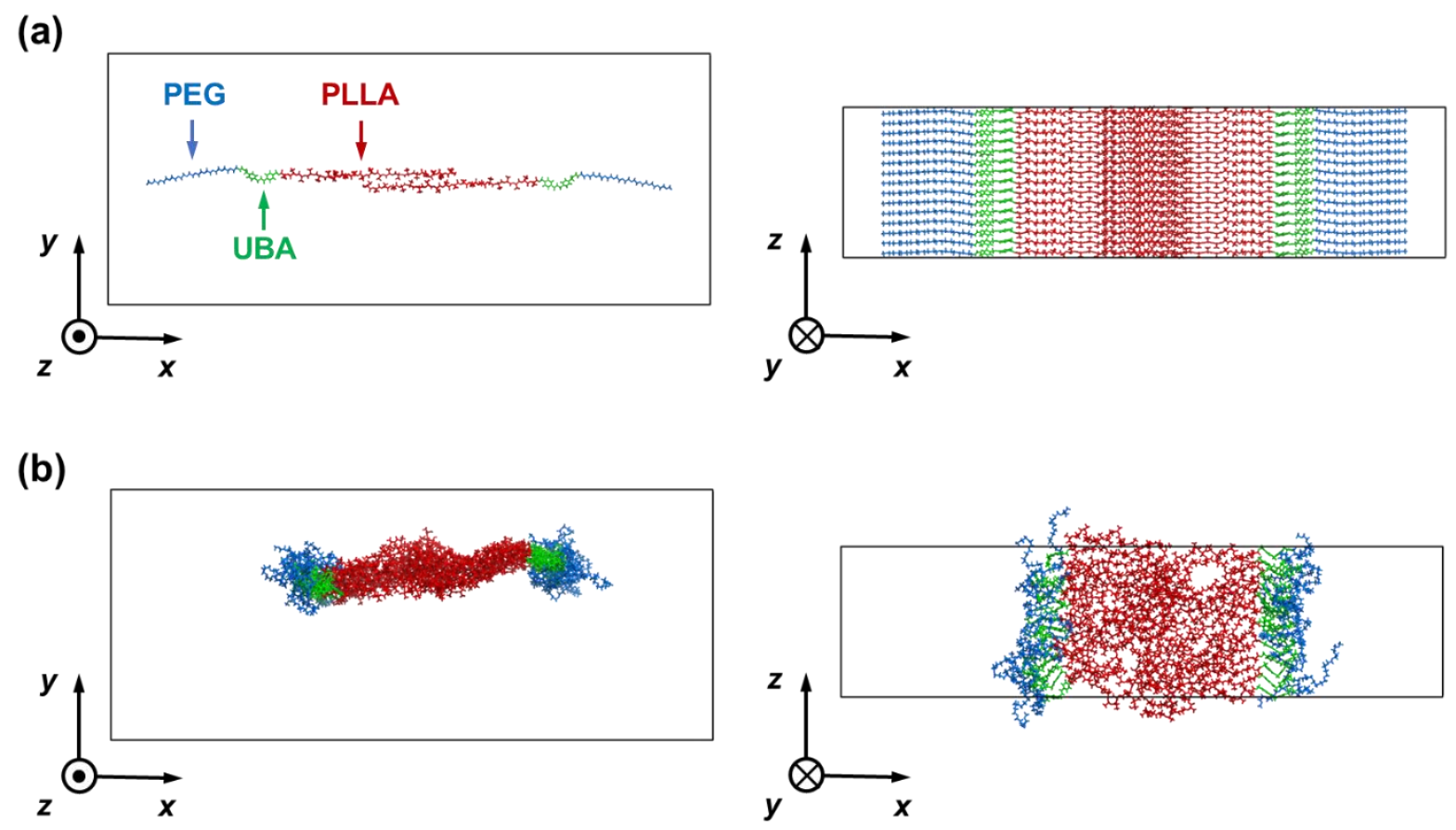

Figure S6. MD simulation snapshots of $\mathrm{PEG}_{10}-\mathrm{UBA}^{-\mathrm{PLLA}_{10}}$ (a) at the initial state and (b) at $10 \mathrm{~ns}$ of the equilibration run.

For investigating the orientational order of UBA and PLLA segments of the assemble structure at the equilibrated state, the order parameters were calculated for the long axis vectors of UBA, PLLA segments, and each PLLA monomer unit, respectively. The order parameter was estimated as the largest positive eigenvalue of the tensor order parameter, $P_{\alpha \beta}$ defined as the following equation:

$$
P_{\alpha \beta}=\frac{1}{N} \sum_{i=1}^{N} \frac{1}{2}\left(3 n_{i \alpha} n_{i \beta}-\delta_{\alpha \beta}\right)
$$

where $N$ is the number of PEG $_{10}$-UBA-PLLA 10 molecules or the total number of LLA monomer units in the system, subscripts $\alpha$ and $\beta$ represent the coordinates $x, y$, and $z$, and $\boldsymbol{n}_{i}$ is the normalized vector 
connecting two end atoms of each segment of the $i$-th molecule or the $i$-th LLA monomer unit. The time profiles of the order parameters of UBA, PLLA segments, and LLA monomer units are shown in Figure S7.

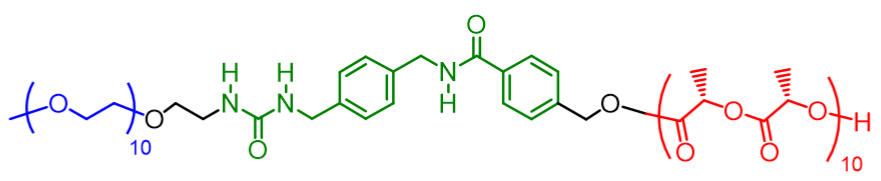

(a)

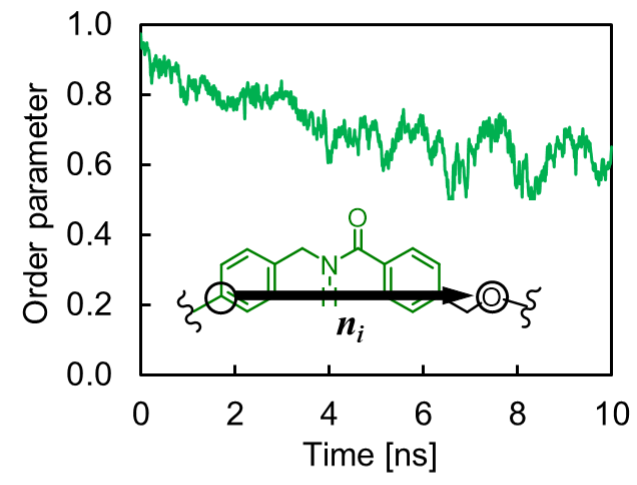

(b)

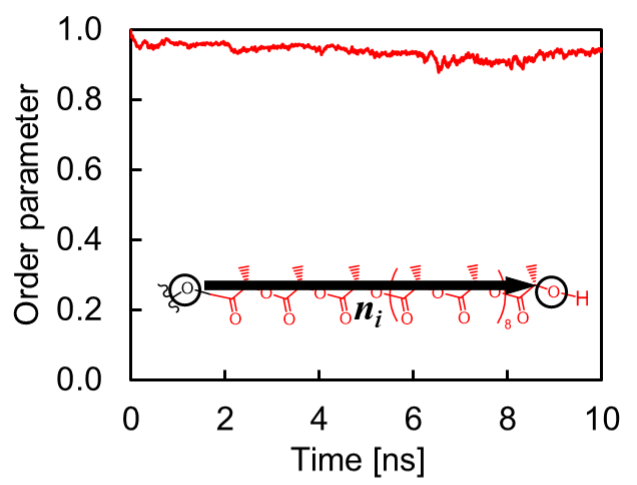

(c)

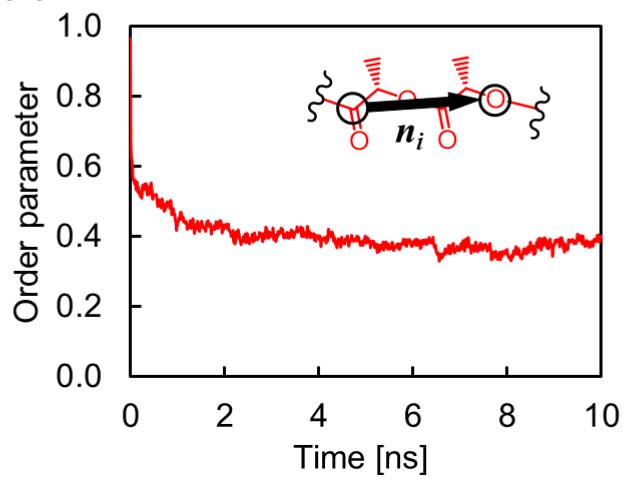

Figure S7. Time profiles of order parameter for (a) UBA, (b) PLLA segments of PEG $10-U B A-$ PLLA $_{10}$ and (c) LLA monomer units in PEG $_{10}-\mathrm{UBA}_{-P L L A}$. Each inset shows the vector $\left(\boldsymbol{n}_{i}\right)$ connecting two end atoms of the group.

The order parameter of the UBA decreased because the UBA structure is bent and twisted at the equilibrated state (Figure S7a). That of PLLA chains is almost unchanged (Figure S7b), indicating that 
the vector between both ends of the PLLA chain is remained, while the middle part of the chain is curved, winded, and not perfectly ordered as that based on the end-to-end vector of the LLA monomer unit drastically decreased within 1 ns (Figure S7c).

Estimation of the size of PEG and PLLA chains of 1a. According to previous reports by Kawaguchi, PEG is expected to form random coils in water. ${ }^{16}$ Thus, the size of PEG is estimated as a double of the root-mean-square radius of gyration $\left(2\left\langle S^{2}\right\rangle^{1 / 2}\right)$. Conformation of flexible polymers is often discussed with the wormlike chain model, ${ }^{17}$ in which the mean-square end-to-end distance $\left\langle R^{2}\right\rangle$ is represented by $\left\langle R^{2}\right\rangle=L / \lambda-1 / 2 \lambda^{2}[1-\exp (-2 \lambda L)]$ where $L$ is the contour length and $\lambda^{-1}$ is the stiffness parameter. The contour length $L$ is calculated from the ratio of the number average molecular weight $M_{\mathrm{n}}$ to the molar mass per unit contour length $M_{\mathrm{L}}\left(M_{\mathrm{L}}=M_{\mathrm{n}} / L\right)$. For PEG of 1a, $M_{\mathrm{n}}$ is 5000 and $M_{\mathrm{L}}$ and $\lambda^{-1}$ were previously determined as $157 \mathrm{~g} \mathrm{~mol}^{-1} \mathrm{~nm}^{-1}$ and $1.1 \mathrm{~nm}$, respectively. ${ }^{16}$ When the stiffness parameter is small (typically $\lambda^{-1}<2 \mathrm{~nm}$ ), the chain is regarded as Gaussian. ${ }^{18}$ Then, $\left\langle R^{2}\right\rangle$ is represented as $6\left\langle S^{2}\right\rangle \cdot{ }^{17}$ Therefore, the size of PEG of $\mathbf{1 a}$ in water is estimated by $4.8 \mathrm{~nm}$ from $2\left\langle S^{2}\right\rangle^{1 / 2}=$ $2(1 / 6)^{1 / 2}\left\langle R^{2}\right\rangle^{1 / 2}$.

The PLLA chain is also considered as the wormlike chain model, and each parameter was determined in the previous study: ${ }^{18} M_{\mathrm{L}}=350 \mathrm{~g} \mathrm{~mol}^{-1} \mathrm{~nm}^{-1}$ and $\lambda^{-1}=6.5 \mathrm{~nm} . M_{\mathrm{n}}$ of PLLA in 1a is calculated from the degree of polymerization (m) in Table 1 that is 38 , providing 5472 . Then, $L$ is conduced to $15.6 \mathrm{~nm}$ that gives the root-mean-square end-to-end distance $\left\langle R^{2}\right\rangle^{1 / 2}$ as the size of the PLLA chain in the assemblies of $\mathbf{1 a}$ to be $9.0 \mathrm{~nm}$.

The lengths of 10-mers of PEG and PLLA of a model polymer used in all-atom MD simulation were calculated in the same way, using $M_{\mathrm{n}} 440$ for 10 -mer of PEG and $M_{\mathrm{n}} 1440$ for 10-mer of PLLA, respectively. 
Coarse-grained MD simulation. In hydrophilic and hydrophobic copolymer systems, the stability of the assembled structure depends on the interfacial tension between the solvent and the polymer assembly, where many small spheres appear in low interfacial tension, and several disks or lamellae appear in high interfacial tension. ${ }^{19}$ We examine the stability of a disk structure by coarse-grained MD simulations.

(a)

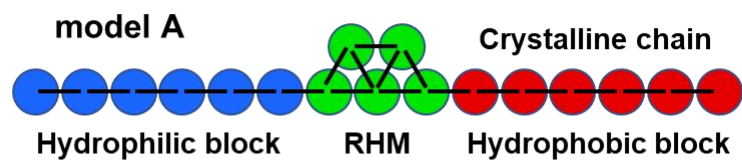

(b)

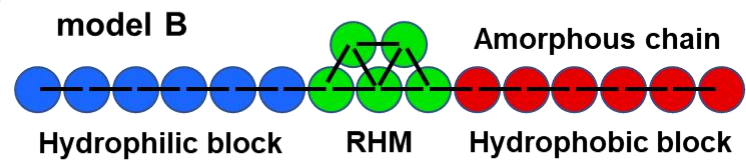

(c)

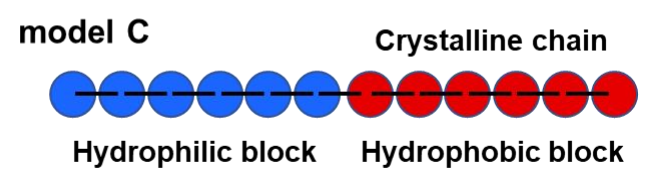

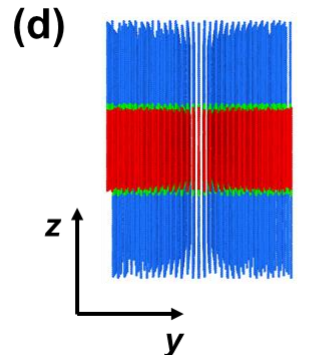

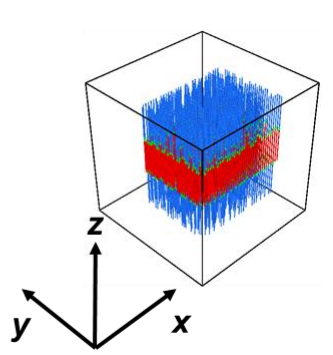

(e)
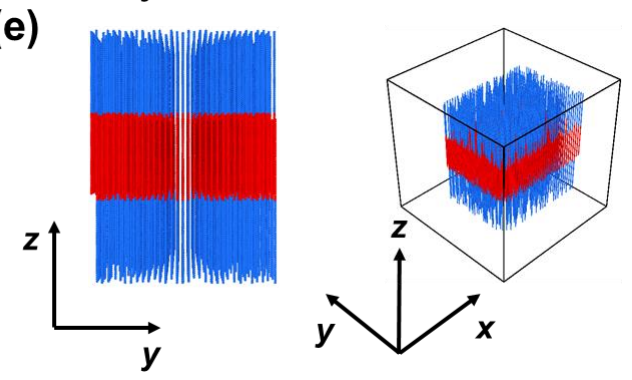

Figure S8. Coarse-grained models for amphiphilic block copolymers consisting of a hydrophilic block, RHM, and a crystalline hydrophobic block (model A) (a), consisting of a hydrophilic block, RHM, and an amorphous hydrophobic block (model B) (b), and consisting of hydrophilic and crystalline hydrophobic blocks (model C) (c). Initial structures of the disk-like assemblies for model A and model B (d), and model C (e) in $N_{\text {hydrophilic }}=40$ and $N_{\text {hydrophobic }}=40$.

Coarse-grained MD simulations are performed using a bead-spring model under a threedimensional periodic boundary condition. Copolymers consisting of a hydrophilic block, RHM, and a crystalline hydrophobic block are defined as model A (Figure S8a) where the hydrophilic and crystalline hydrophobic blocks are represented by flexible and semiflexible chains, respectively. The RHM part consists of five beads corresponding to two benzene rings by using the MARTINI model. ${ }^{20}$ The 
amorphous hydrophobic part of model B is represented by a flexible polymer chain (Figure S8b). The other parts are the same as those of model A. The different hydrophobic chains in the coarse-grained simulation are designed to reveal the effects of the crystalline nature of the hydrophobic block on the assembly. Model C consists of hydrophilic and crystalline hydrophobic blocks without the RHM part (Figure S8c). The contribution of the RHM part to the assembled structure is proved by comparing the simulation for model A (with RHM) and model C (without RHM). The number of hydrophilic ( $\left.N_{\text {hydrophilic }}\right)$ and hydrophobic $\left(N_{\text {hydrophobic }}\right)$ beads in a molecule is 40 , respectively. We set 1000 molecules in a disk-like assembly at the initial structure, as shown in Figure S8d and e. The temperature is increased from $200 \mathrm{~K}$ to $300 \mathrm{~K}$ in $10^{6}$ simulation steps for the relaxation calculation. Then, the product run at $300 \mathrm{~K}$ in $10^{6}$ simulation steps is performed for equilibration.

To represent copolymers including the crystalline part, we adopted the potential energy and parameters used for the crystallization of polyethylene. ${ }^{21}$ The unit length and energy are represented by $a=0.392 \mathrm{~nm}$ and $\varepsilon=598.64 \mathrm{~J} \mathrm{~mol}^{-1}$. The beads are connected by harmonic springs:

$$
U_{\text {bond }}=1 / 2 k_{\text {bond }}\left(l-l_{0}\right)^{2}
$$

where $k_{\text {bond }}=3.5 \times 10^{25} \mathrm{~J} \mathrm{~m}^{-2} \mathrm{~mol}^{-1}$ is the spring constant, $l$ is the bond length between neighboring beads, and $l_{0}=0.393 a$ is the averaged bond length. The bonds connecting the adjacent beads are indicated by solid lines in Figure S8a-c. The following potential was used for bond angle bending:

$$
U_{\text {bend }}=k^{a} \text { bend }-k_{\text {bend }}^{b}\left(\cos \theta-\cos \theta_{0}\right)+k_{\text {bend }}^{d}\left(\cos \theta-\cos \theta_{0}\right)^{3}
$$

where $k^{a}$ bend, $k^{b}$ bend, and $k^{d}$ bend are coefficients for bending stiffness, $\theta$ is the angle between adjacent bond vectors, $\theta_{0}$ decides the stable angles. By using the bending potential, the linear state is the most stable, the perpendicular state is metastable, and an energy barrier exists between them. The coefficients for the hydrophobic part in the crystalline polymer are as follows: $k^{a}$ bend $=12.428 \varepsilon, k^{b}$ bend $=38.370 \varepsilon, k^{d}$ bend $=$ $123.38 \varepsilon$, and $\theta_{0}=108.78(\mathrm{deg})$. The coefficients are set to zero for the hydrophilic, RHM, and 
amorphous hydrophobic parts. The Lennard-Jones potential, $U_{\mathrm{LJ}}$, includes the excluded volume and attractive interactions:

$$
U_{\mathrm{LJ}}=4 \varepsilon^{\prime}\left[(\sigma / r)^{12}-(\sigma / r)^{6}\right]
$$

where $\varepsilon^{\prime}$ is the depth of the potential, $r$ is the distance between two beads, and $\sigma$ is the averaged bead diameter. Interactions between beads less than three bonds apart are neglected. The coefficients are set as $\varepsilon^{\prime}=4 \varepsilon$ and $\varepsilon^{\prime}=\varepsilon$ for RHM-RHM interactions and the other pairs, respectively. The attractive interaction between RHM parts was estimated by that between benzene rings reported by the previous study. ${ }^{22}$ Cut-off lengths of $2.0 a, 3.0 a$, and $2^{1 / 6} a$ are adopted for the hydrophobic-hydrophobic interactions, RHM-RHM interactions, and interaction for the others, respectively. The diameters of beads for hydrophilic, RHM, and hydrophobic parts are set as $1.0 a, 1.2 a$, and 1.0a, respectively. The beads obey the stochastic dynamics described by the Langevin equation with the drag coefficient, $\gamma=$ 0.5 . The mass, $m=14 \mathrm{~g} \mathrm{~mol}^{-1}$, is set equivalently for all beads. The time unit was chosen to be $\tau=$ $a(m / \varepsilon)^{1 / 2}$, which corresponds to $1.9 \mathrm{ps}$ in real-time units. The time step is set to $d t=5.0 \times 10^{-3} \tau$. The Brownian force satisfies the fluctuation-dissipation theorem.

The two-dimensional gyration radius of hydrophobic parts in the $x y$-plane, in which the molecules are initially aligned, is calculated during the product run. The reference value is taken at $t=0$. The difference of gyration radius, $\Delta R_{\mathrm{gxy}}$, indicates the expansion of the disk structure, reflecting the stability of the disk. The following equation calculates the orientational order of RHM: $\frac{1}{2}\left(3\left\langle\cos ^{2} \phi\right\rangle-\right.$ 1 ), where $\phi$ is the angle between the vectors indicated in Figure S9e. The bracket, $\langle\ldots\rangle$, indicates the averaging over the pairs if the distance between the center of RHM is less than 3.0a (cut-off length for the RHM-RHM interaction). 
(a)

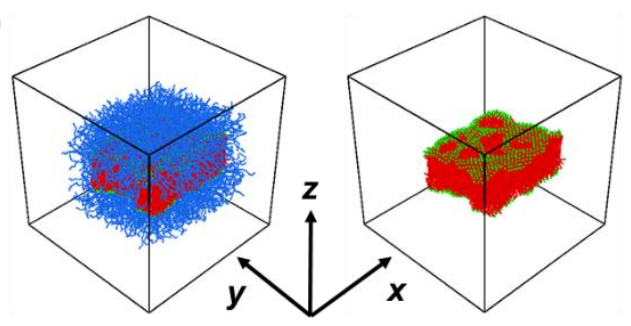

(b)

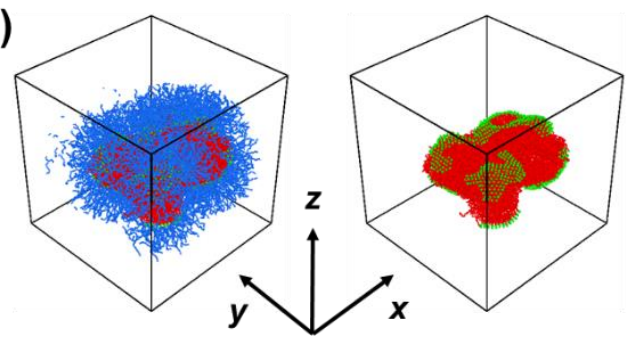

(c)

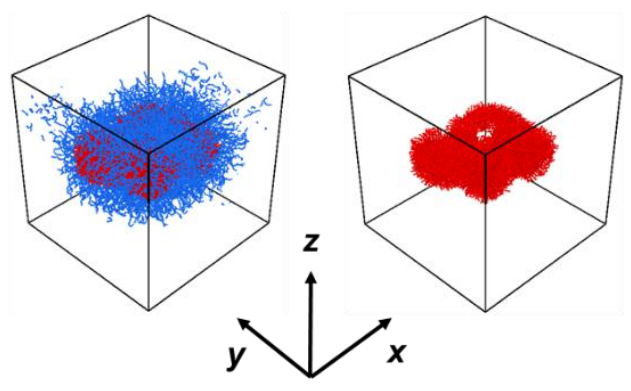

(d)

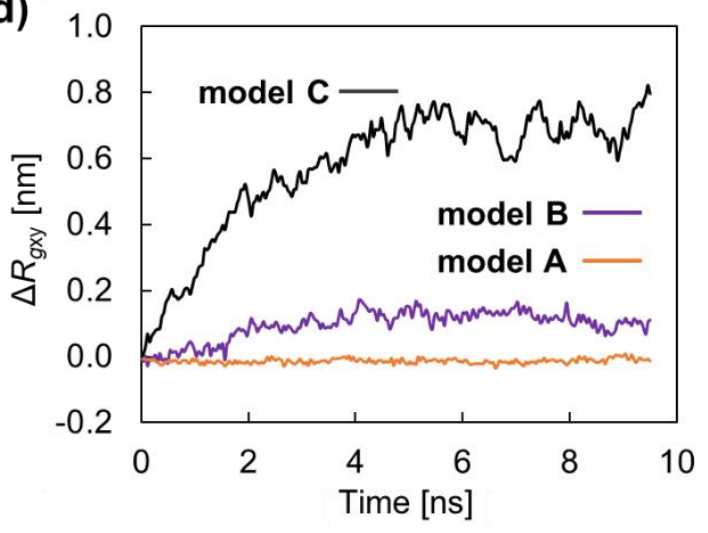

(e)

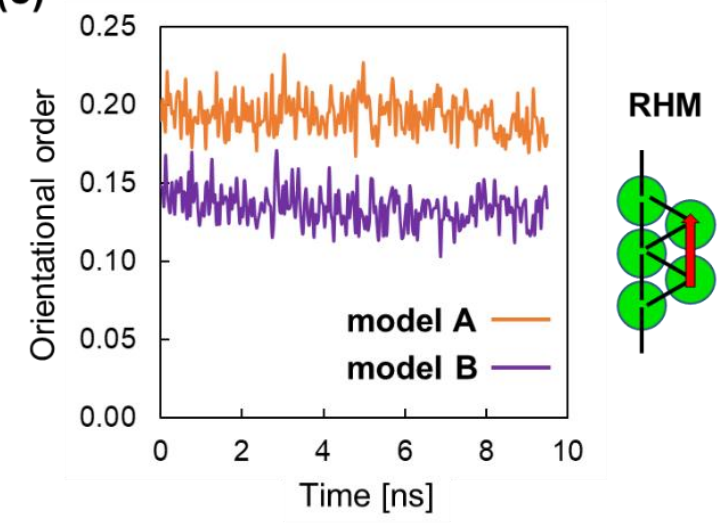

Figure S9. Typical snapshots of disk-like assemblies for model A (a), model B (b), and model C (c) in $N_{\text {hydrophilic }}=40$ and $N_{\text {hydrophobic }}=40$ at $t=5000 \tau$, which corresponds to $9.5 \mathrm{~ns}$, in the product run. For easy visualization, the hydrophilic polymers are transparent in the right snapshots. Time courses of the changes in the gyration radius of hydrophobic spheres in the $x y$-plane (d) and the orientational order of RHM (e). The reference value is taken at $t=0$. The increase in $\Delta R_{\text {gxy }}$ indicates the collapse of the disk structure. The orientation of the RHM part is defined by the vector shown at the right of (e). The higher orientation order for model A than that for B indicates that the crystalline hydrophobic part maintains the stability of the disk-like structure.

Scattering angle dependence of dynamic light scattering (multiangle DLS). The water dispersion containing the polymer assemblies was placed in a $20 \phi$ quartz cylindrical cuvette after treating with a syringe filter ( $0.45 \mu \mathrm{m}$ sized pores; cellulose acetate) at least three times. The measurement was performed at $25{ }^{\circ} \mathrm{C}$ on a DLS-7000 (Otsuka Electronics) using a He-Ne laser $(10 \mathrm{~mW})$ with a wavelength $(\lambda)$ of $632.8 \mathrm{~nm}$ as a light source. The scattering was measured every $10^{\circ}$ at the angle $(\theta)$ 
ranging from 30 to $70^{\circ}$ and every $20^{\circ}$ at that from 90 to $150^{\circ}$. Autocorrelation function $g^{(2)}(t)^{-1}$ was processed by CONTIN analysis to obtain relaxation spectra $A(\tau)$. The first cumulant of autocorrelation function, $\Gamma$ was estimated from the following equation:

$$
\Gamma=\lim _{q \rightarrow 0} \frac{\sum A(\tau) / \tau}{\sum A(\tau)}
$$

where $\tau$ is a relaxation time. The translational diffusion coefficient, $D$ of isotropic particles was given by $D=\Gamma q^{-2}$, where $q$ is the scattering vector defined by $q=\left(4 \pi n \lambda^{-1}\right) \sin (\theta / 2) . \Gamma q^{-2}$ of anisotropic rod-like particles with a length $(L)$ and diameter $(d)$ was given by the following equation: ${ }^{23-25}$

$$
\Gamma q^{-2}=D_{0}+\frac{L^{2}}{12} \Theta f_{1}\left(\frac{q L}{2}\right)-\left[\frac{1}{3}-f_{2}\left(\frac{q L}{2}\right)\right]\left(D_{3}-D_{1}\right)
$$

where $D_{0}, D_{1}, D_{3}$, and $\Theta$ indicate the average, the sideways and lengthways translational, and the rotational diffusion coefficients of the rod-like particles, respectively. The $f_{1}(q L / 2)$ and $f_{2}(q L / 2)$ values are tabulated in Fujime's report. ${ }^{23}$ Furthermore, $D_{0}$ is given by $\left(2 D_{1}-D_{3}\right) / 3$, and $D_{1}, D_{3}$, and $\Theta$ were represented by the following equations: ${ }^{25}$

$$
\begin{aligned}
& D_{1}=\frac{k_{\mathrm{B}} T}{4 \pi \eta_{0} L}\left[\gamma-0.19+4.2\left(\gamma^{-1}-0.39\right)^{2}\right] \\
& D_{3}=\frac{k_{\mathrm{B}} T}{2 \pi \eta_{0} L}\left[\gamma-1.27+7.4\left(\gamma^{-1}-0.34\right)^{2}\right] \\
& \Theta=\frac{3 k_{\mathrm{B}} T}{\pi \eta_{0} L^{3}}\left[\gamma-1.45+7.5\left(\gamma^{-1}-0.27\right)^{2}\right]
\end{aligned}
$$

where $\gamma$ is denoted by $\ln (2 L / d)$, and $k_{\mathrm{B}}, T$, and $\eta_{0}$ are the Boltzman constant, absolute temperature, and viscosity of medium, respectively. The value of $0.890 \mathrm{mPa}$ s was used as viscosity of water at $25^{\circ} \mathrm{C}$. The $\Gamma q^{-2}$ value obatained at each scattering angle $\theta$ was plotted against $q$, and the plot was fitted by using the equation (S6) for the rod-like particles with various ratios of $L$ to $d$. 


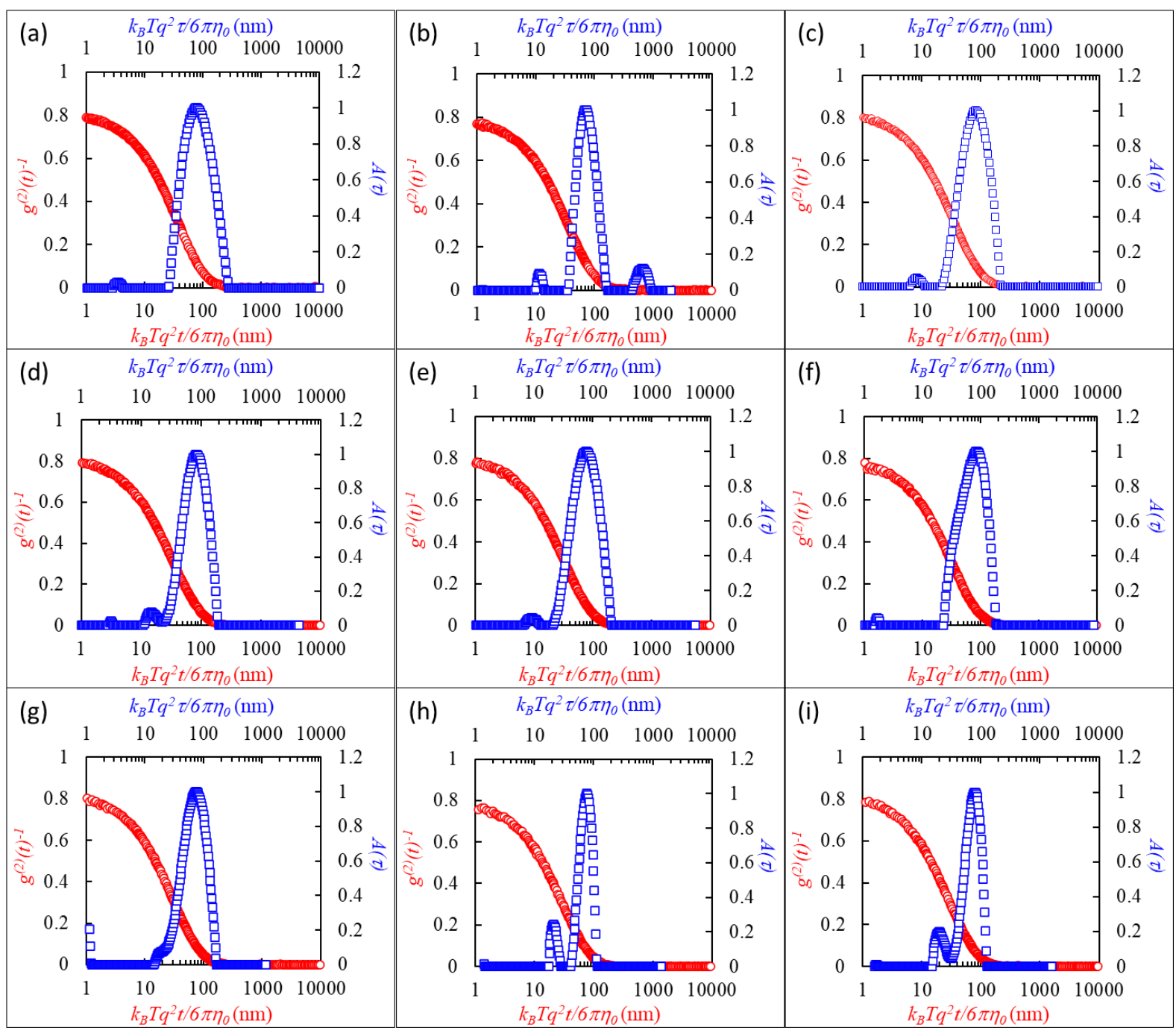

Figure S10. Autocorrelation functions (red) and relaxation spectra (blue) for water dispersion of 1a $(0.05 \mathrm{w} / \mathrm{v} \%)$ at $25^{\circ} \mathrm{C}$. The scattering angles are (a) $30^{\circ}$, (b) $40^{\circ}$, (c) $50^{\circ}$, (d) $60^{\circ}$, (e) $70^{\circ}$, (f) $90^{\circ},(\mathrm{g})$ $110^{\circ}$, (h) $130^{\circ}$, and (i) $150^{\circ}$. 


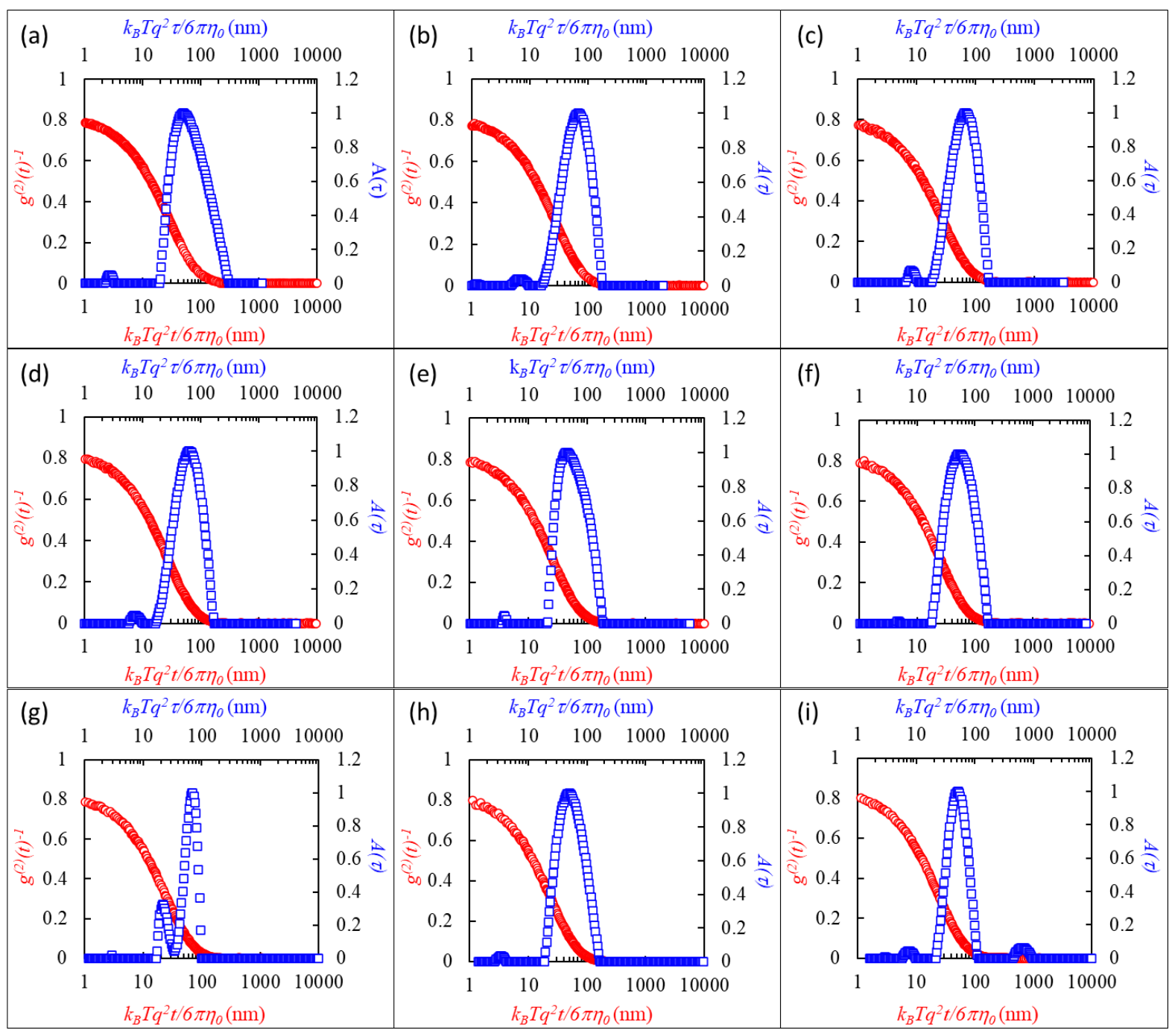

Figure S11. Autocorrelation functions (red) and relaxation spectra (blue) for water dispersion of $\mathbf{1 b}$ $\left(0.05 \mathrm{w} / \mathrm{v} \%\right.$ ) at $25^{\circ} \mathrm{C}$. The scattering angles are (a) $30^{\circ}$, (b) $40^{\circ}$, (c) $50^{\circ}$, (d) $60^{\circ}$, (e) $70^{\circ}$, (f) $90^{\circ}$, (g) $110^{\circ}$, (h) $130^{\circ}$, and (i) $150^{\circ}$. 


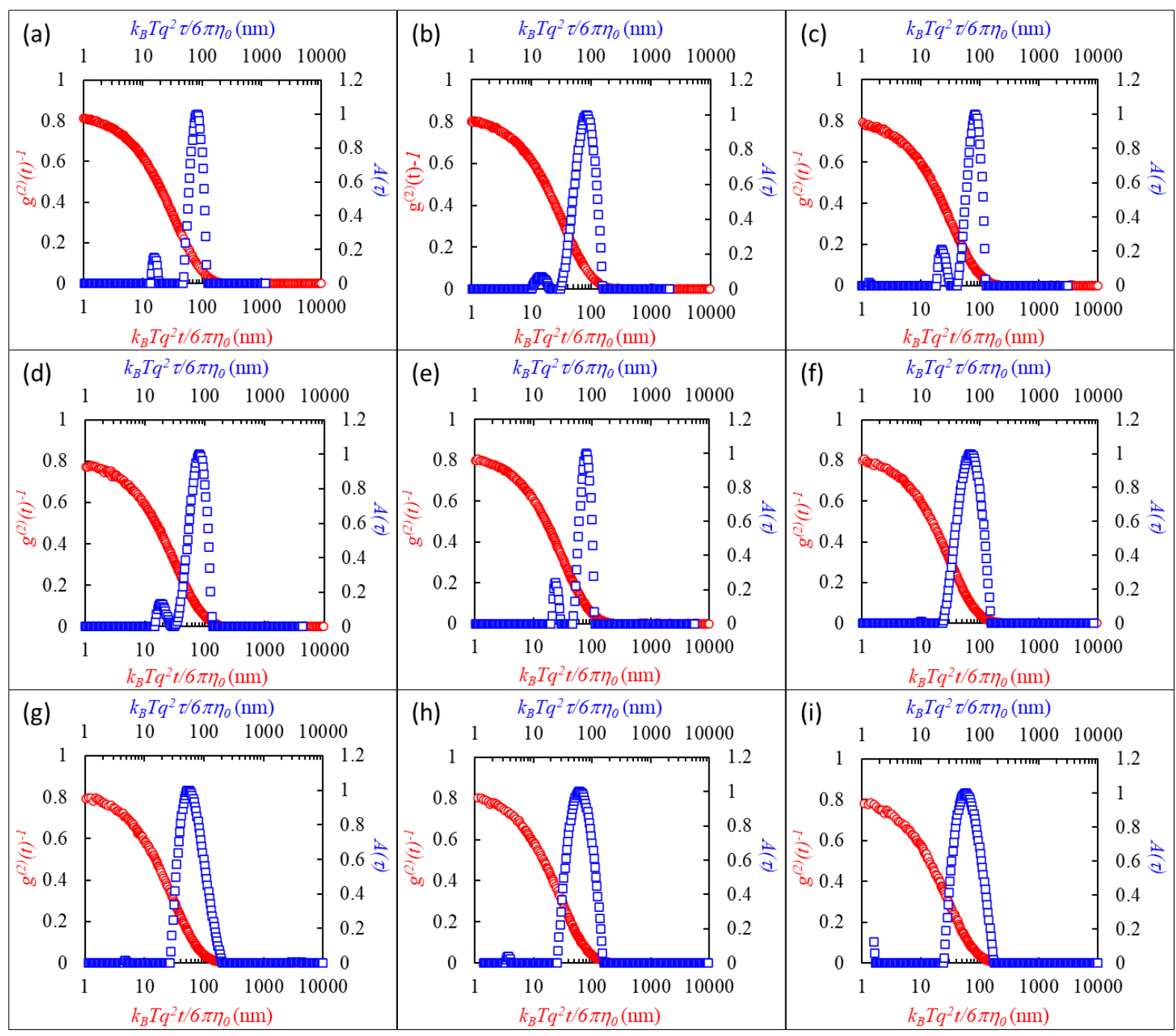

Figure S12. Autocorrelation functions (red) and relaxation spectra (blue) for water dispersion of 1c $(0.05 \mathrm{w} / \mathrm{v} \%)$ at $25^{\circ} \mathrm{C}$. The scattering angles are (a) $30^{\circ}$, (b) $40^{\circ}$, (c) $50^{\circ}$, (d) $60^{\circ}$, (e) $70^{\circ}$, (f) $90^{\circ},(\mathrm{g})$ $110^{\circ}$, (h) $130^{\circ}$, and (i) $150^{\circ}$. 

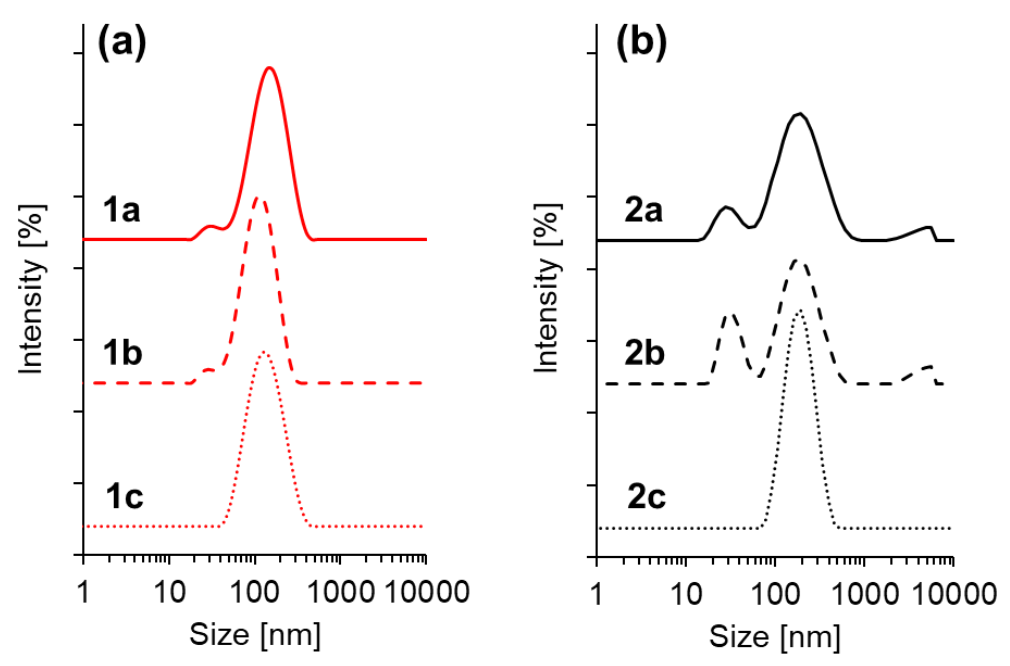

Figure S13. Scattering intensity-averaged particle size distributions of the block copolymer assemblies in water obtained by DLS: (a) 1a, 1b, and 1c, (b) 2a, 2b, and 2c. Polymer dispersions were prepared by nanoprecipitation to be a concentration of $1.0 \mathrm{w} / \mathrm{v} \%$ and stored at $4{ }^{\circ} \mathrm{C}$ for more than 2 weeks. Polymer concentration was diluted to $0.05 \mathrm{w} / \mathrm{v} \%$ for the DLS measurements.

\section{Atomic force microscopy (AFM) observation of the block copolymer assemblies in water. AFM}

imaging was performed using a tip scan high-speed AFM BIXAM (Olympus, Tokyo, Japan) improved based on a previously developed prototype $\mathrm{AFM} .{ }^{26}$ The $1.0 \mathrm{w} / \mathrm{v} \%$ polymer dispersions prepared by the nanoprecipitation were diluted with PBS to adjust the concentration to $0.1 \mathrm{w} / \mathrm{v} \%$. A drop $(2.0 \mu \mathrm{L})$ of the dispersion was deposited onto a mica ( $3 \mathrm{~mm}$ diameter) surface, which was previously treated with 0.05 w/v\% 3-aminopropyl triethoxysilane (APTES) and incubated for $5 \mathrm{~min}$ at room temperature. ${ }^{27}$ The surface was rinsed with PBS and finally covered by PBS $(120 \mu \mathrm{L})$ for observation. Small cantilevers $(9$ $\mu \mathrm{m}$ long, $2 \mu \mathrm{m}$ wide, and $130 \mathrm{~nm}$ thick; BL-AC10EGS, Olympus) with a spring constant of $\sim 0.1 \mathrm{~N} \mathrm{~m}^{-1}$ and a resonant frequency of $\sim 300-600 \mathrm{kHz}$ in water were used to scan the sample surface. Typically, images of $320 \times 240$ pixels were obtained at a scan rate of 0.2 frames $^{-1}$, which were analyzed using AFM scanning system software (Olympus). 

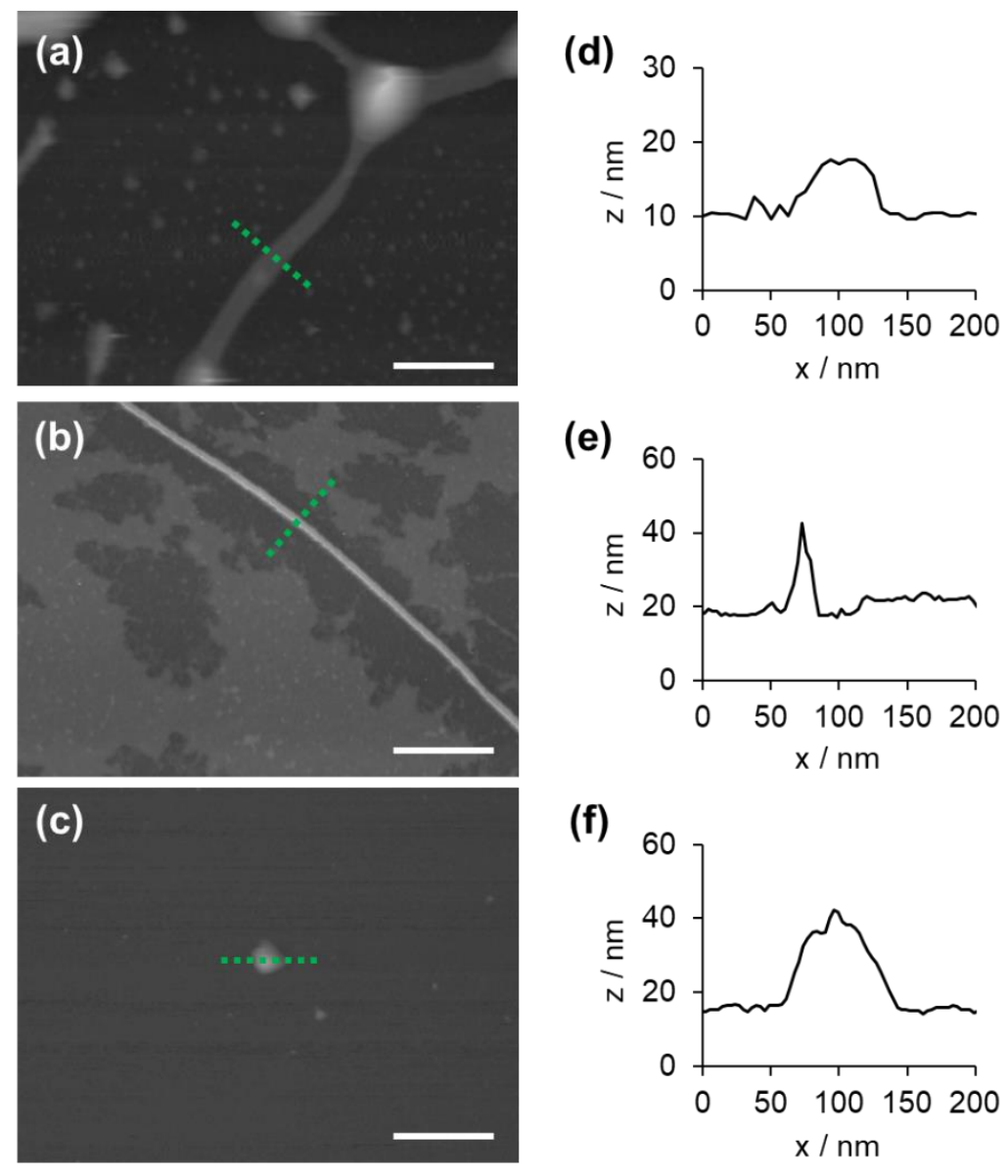

Figure S14. Representative AFM images of the assemblies of 1 covered by PBS (a-c) and cross-section profiles of the green dotted lines in each image $(d-f) .(a, d) \mathbf{1 a},(b, e) \mathbf{1 b}$, and $(c, f) \mathbf{1 c}$. The bar scales represent $200 \mathrm{~nm}$.

Materials for cell culture experiments. Phosphate buffered saline (PBS) was formulated by dissolving a PBS tablet (Takara Bio, Shiga, Japan) in Milli-Q water (1 L). Minimum Essential Medium Eagle, Alpha Modification ( $\alpha-\mathrm{MEM})$, and 4\% paraformaldehyde phosphate buffer solution (4\% PFA) were purchased from FUJIFILM Wako Pure Chemicals. Penicillin-streptomycin liquid (P/S), and 0.25\% trypsin/ethylenediaminetetraacetic acid (EDTA) (trypsin/EDTA) were purchased from Gibco. Fetal bovine serum (FBS) was purchased from BioWest (Nuaillé, France). Triton X-100 and Tween20 were purchased from MP Biomedicals (Irvine, CA, USA) and used as PBS solutions in 1.0\% and 0.02\%, 
respectively. A blocking reagent Can Get Signal Immunostain Immunoreaction Enhancer Solution B (Can Get Signal) was purchased from TOYOBO (Osaka, Japan). Anti-vinculin antibody Ms X Vinculin was purchased from Chemicon. Alexa Fluor568 goat anti-mouse $\operatorname{IgG}(\mathrm{H}+\mathrm{L})$ and Alexa Fluor488 phalloidin were purchased from Invitrogen. ProLong Gold antifade mountant with 4',6-diamidino-2phenylindole (DAPI) was purchased from Thermo Fischer Scientific (Waltham, MA, USA).

Poly(ethylene terephthalate) (PET) film (thickness $125 \mu \mathrm{m}$ ) was purchased from Mitsubishi Chemical (Tokyo, Japan) and punched into a circle with a diameter of $14 \mathrm{~mm}$ by a manual pressing machine (FK-HP500EX Cam System Handpress, Fukui Kiko Shokai, Osaka, Japan). Cell culture dishes (10 and $6 \mathrm{~cm}$ in diameters) and 24-well and 6-well tissue culture plates comprising tissue-culture polystyrene (TCPS) were purchased from IWAKI (Shizuoka, Japan). 
Cell culture in the presence of polymer assemblies. Cell culture tests with a culture media containing no FBS were also conducted by a similar protocol, except the incubation time $(6 \mathrm{~h})$ and no FBS in any media.
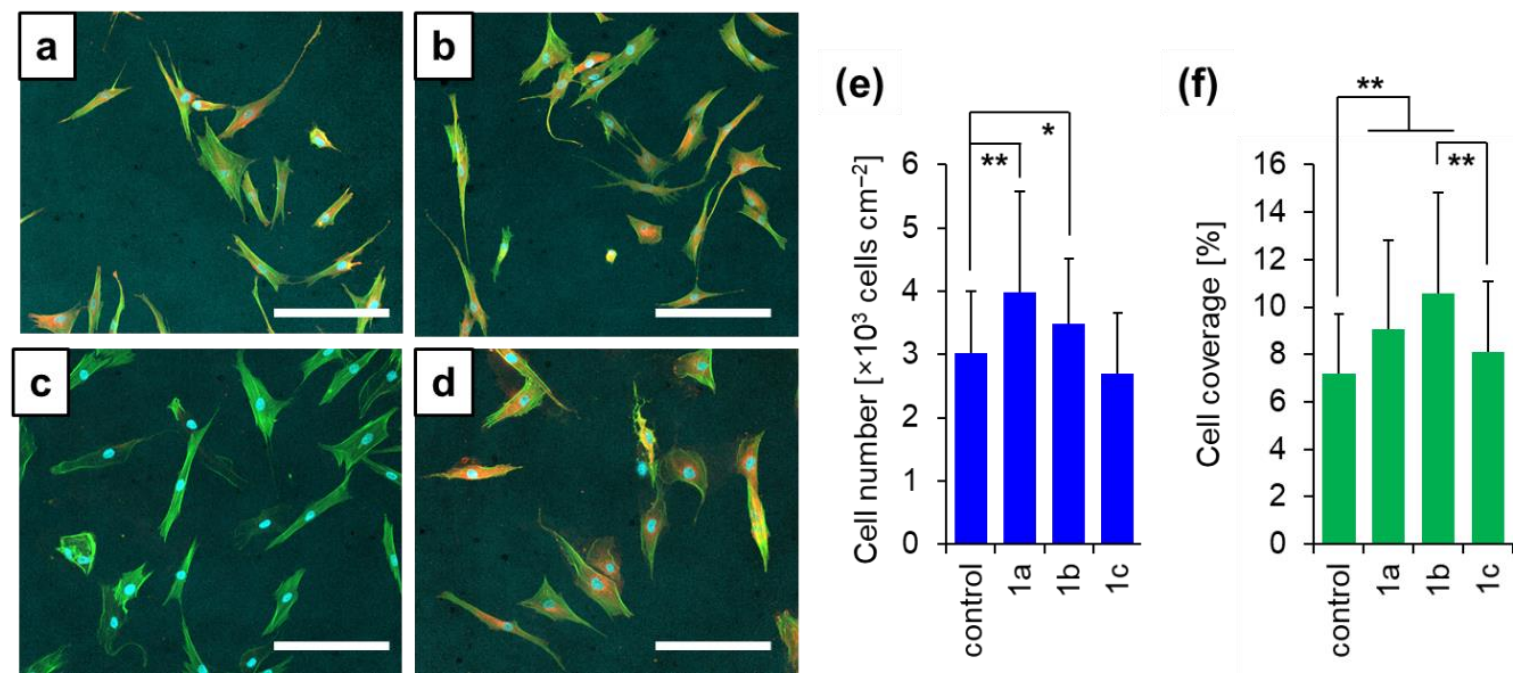

Figure S15. NHDF cultures in the presence of $0.05 \mathrm{w} / \mathrm{v} \%$ block copolymer assemblies incubated for $6 \mathrm{~h}$ with $\alpha$-MEM (including no FBS). Representative confocal images of the NHDF cells cultured with (a) no polymer (control), (b) 1a, (c) 1b, and (d) 1c. The bar scales represent $200 \mu \mathrm{m}$, and the blue, green, and red colorations represent nuclei, the cytoskeleton, and focal adhesion, respectively. (e) Cell number and (f) cell coverage of the NHDFs cultured with the polymer assemblies (mean $\pm \mathrm{SD}, \mathrm{n}=3$ ) 
- in water - in $\alpha-M E M+10 \%$ FBS $\left(37^{\circ} \mathrm{C}, 6 \mathrm{~h}\right)$

- control (no polymer in a-MEM+10\%FBS)
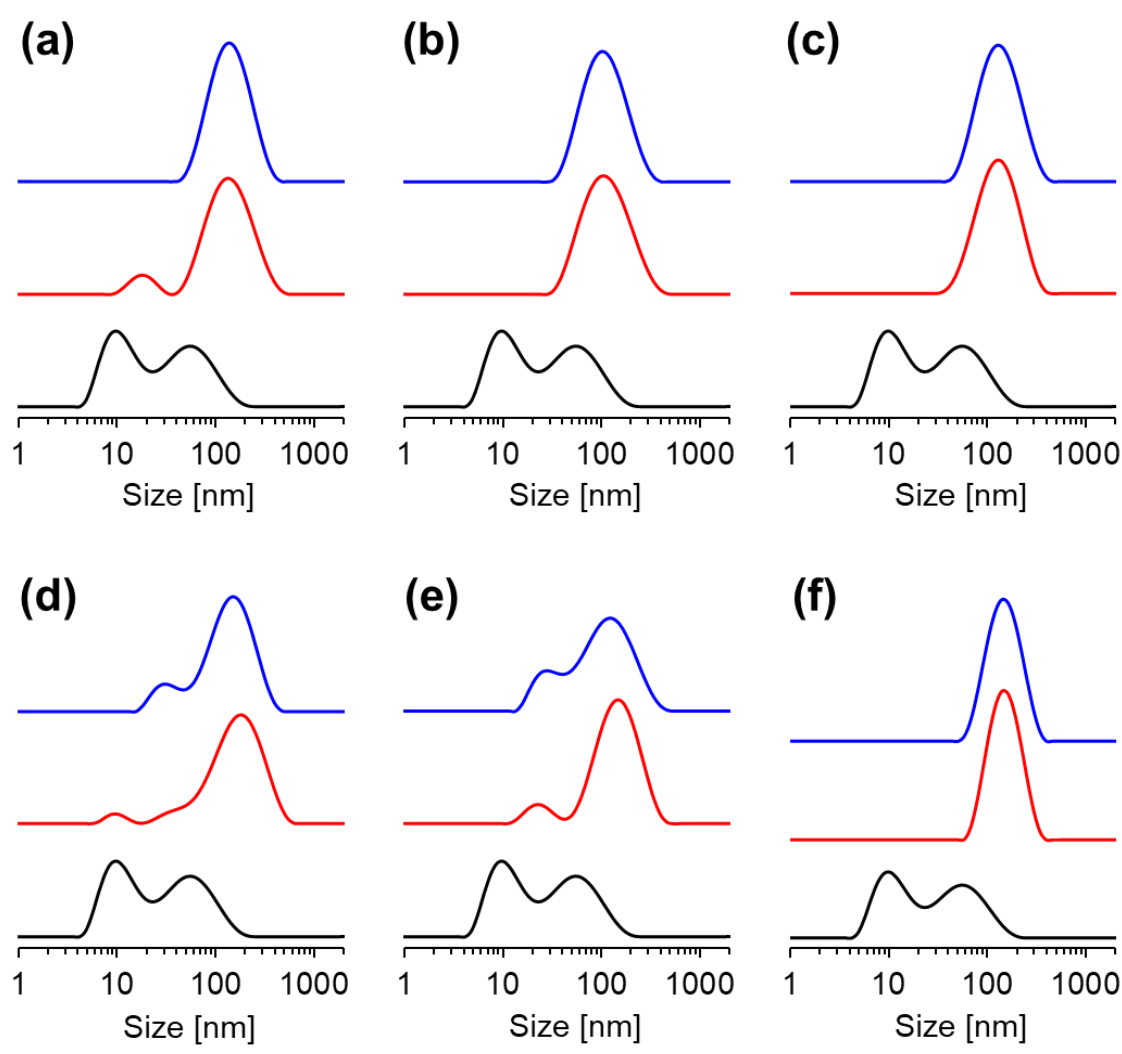

Figure S16. DLS profiles of the block polymer assemblies in water (blue lines) and $\alpha$-MEM containing $10 \%$ FBS incubated for $37^{\circ} \mathrm{C}$ for $6 \mathrm{~h}$ (red lines) and $\alpha$-MEM containing $10 \%$ FBS as a control (black lines). (a) 1a, (b) 1b, (c) 1c, (d) 2a, (e) 2b, and (f) $\mathbf{2 c}$. 

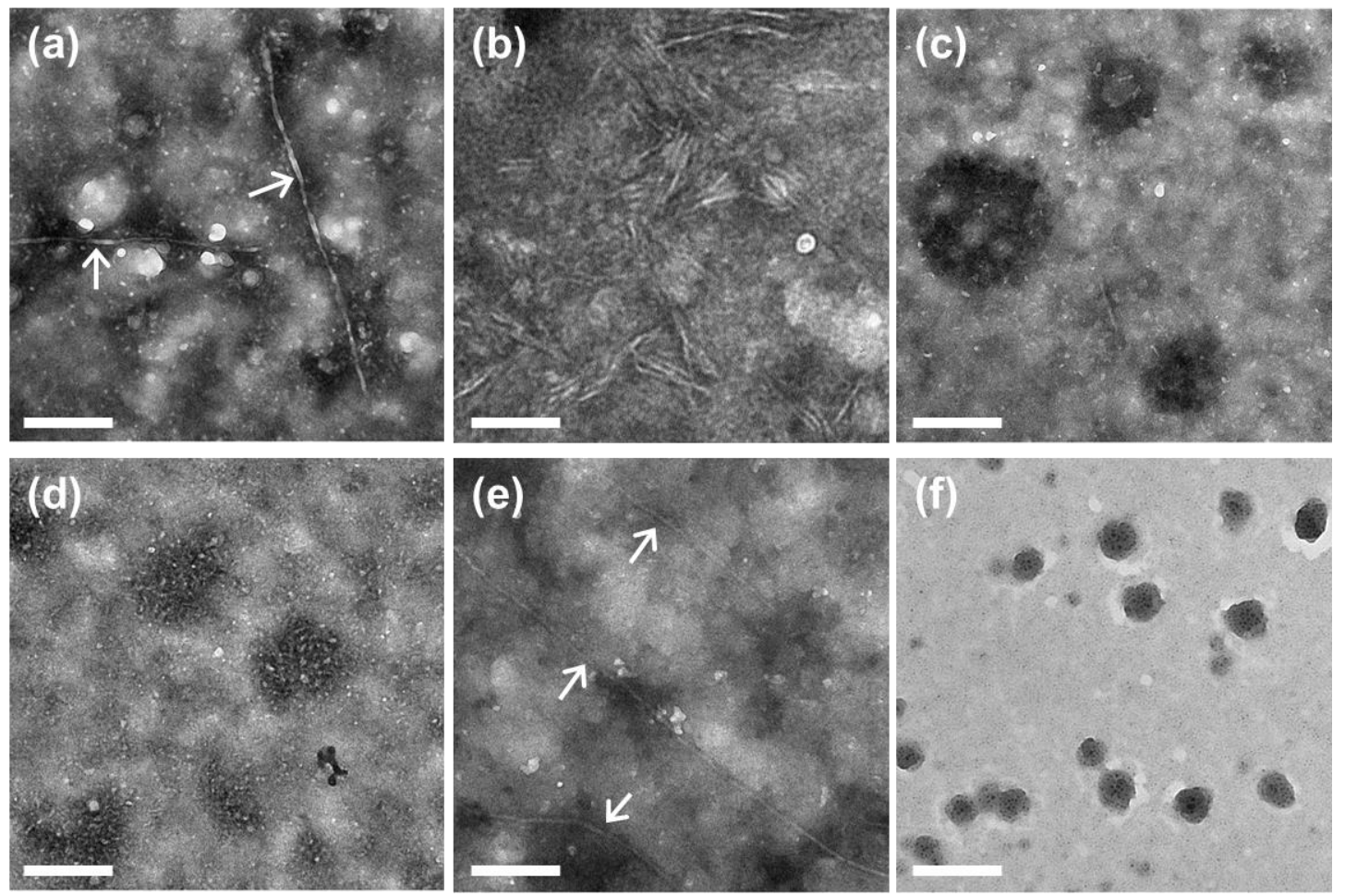

Figure S17. Representative TEM images of the block copolymer assemblies incubated in the standard culture medium ( $\alpha$-MEM containing $10 \% \mathrm{FBS}$ ) at $37^{\circ} \mathrm{C}$ for $6 \mathrm{~h}$ with a polymer concentration of 0.05 w/v\%: (a) 1a, (b) 1b, (c) 1c, (d) 2a, (e) 2b, and (f) 2c. The bar scales represent $200 \mathrm{~nm}$. Arrows indicate representative fibrous nanostructures. 
(a)

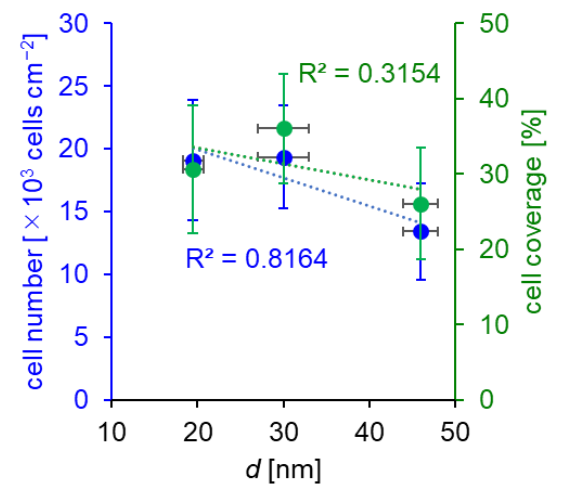

(c)

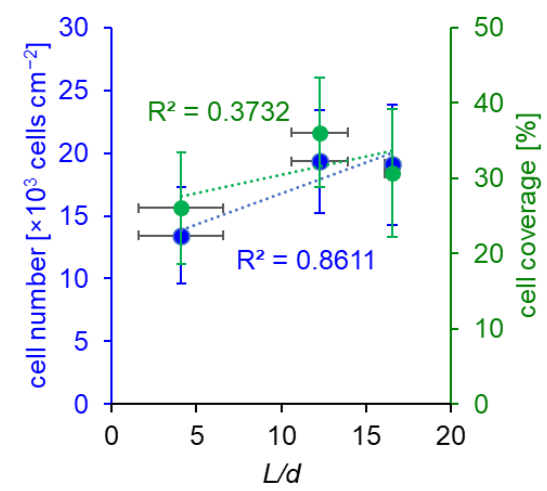

(b)

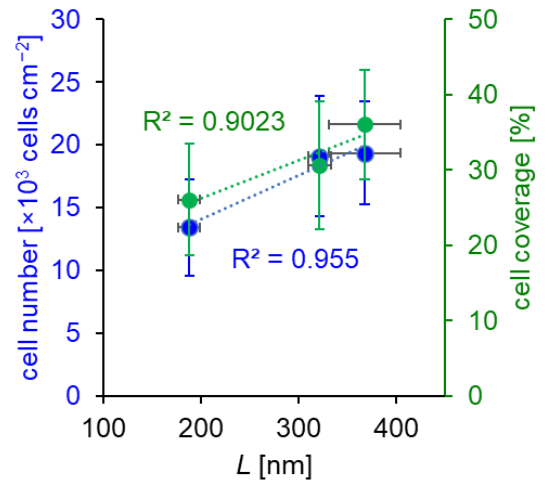

(d)

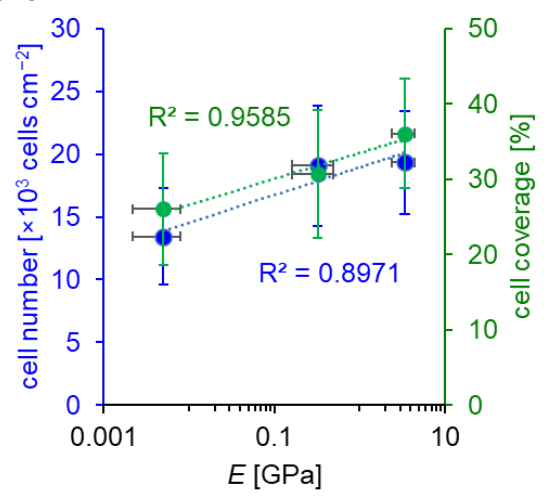

Figure S18. Relationships between cell responses and characteristics of the assemblies of 1: (a) diameter, (b) length, (c) aspect ratio, and (d) reported Young's moduli of hydrophobic blocks. ${ }^{28,29} \mathrm{R}^{2}$ represents linear correlation coefficients at each plot. 


\section{${ }^{1}$ H NMR Spectra Data}

PEG-UBA-OH (3)

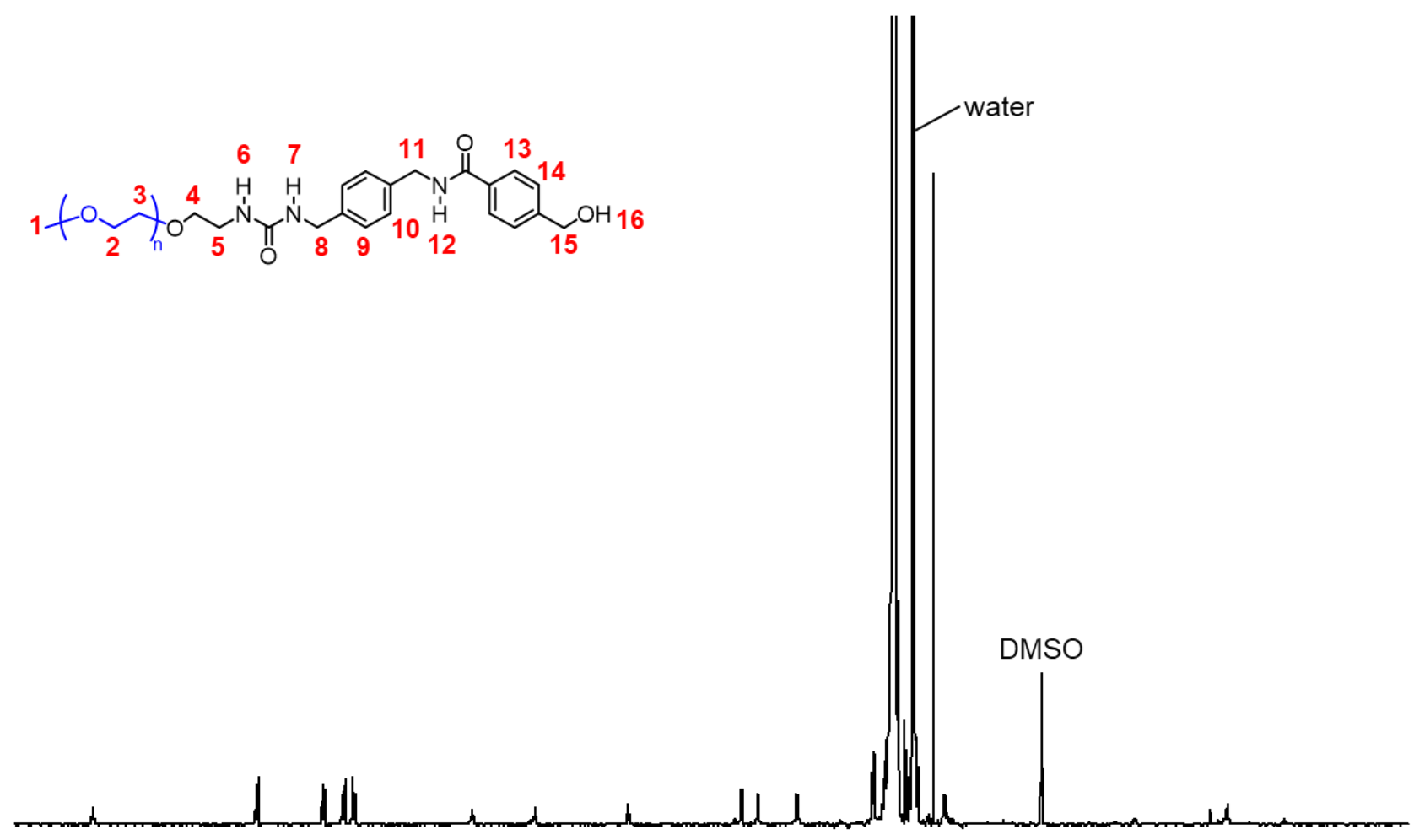

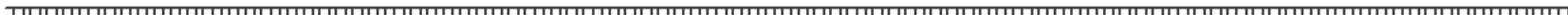

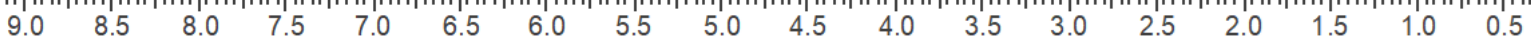
Chemical Shift (ppm) 
PEG-UBA-PLLA (1a)

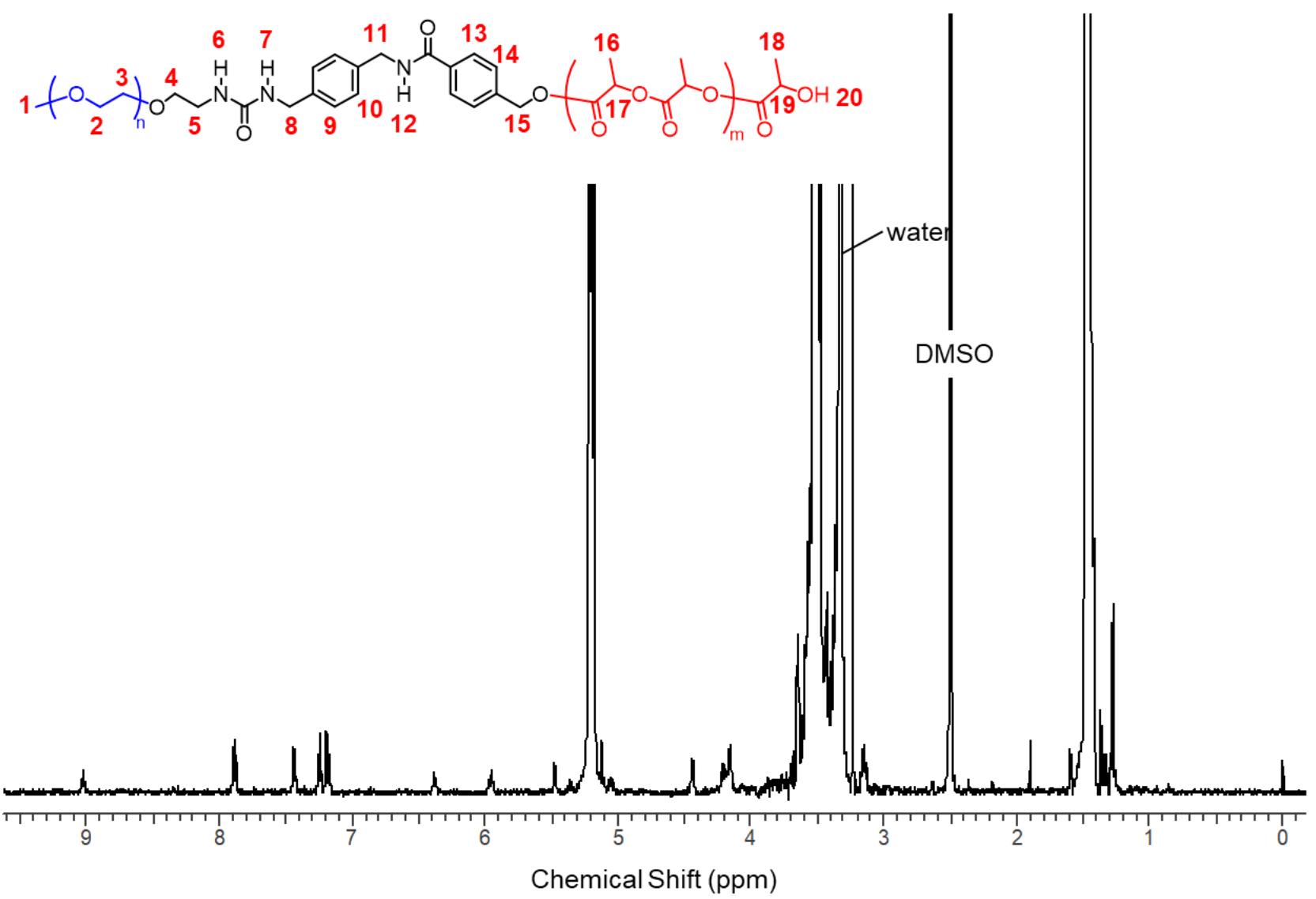


PEG-UBA-PCL (1b)

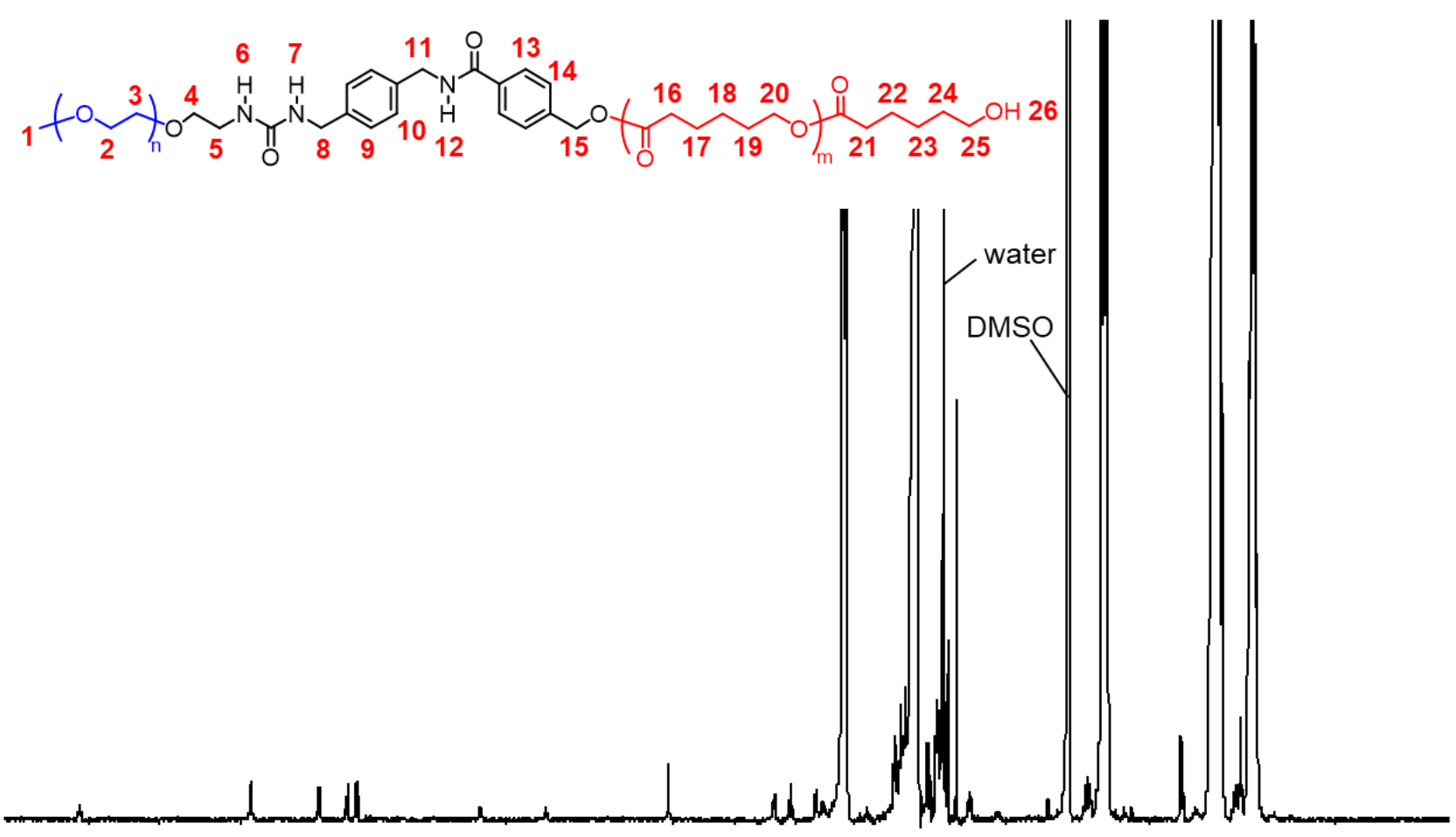

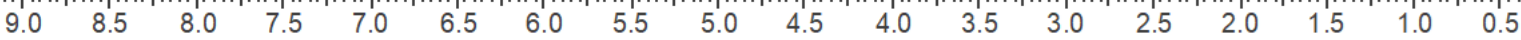
Chemical Shift (ppm) 
PEG-UBA-PTMC (1c)
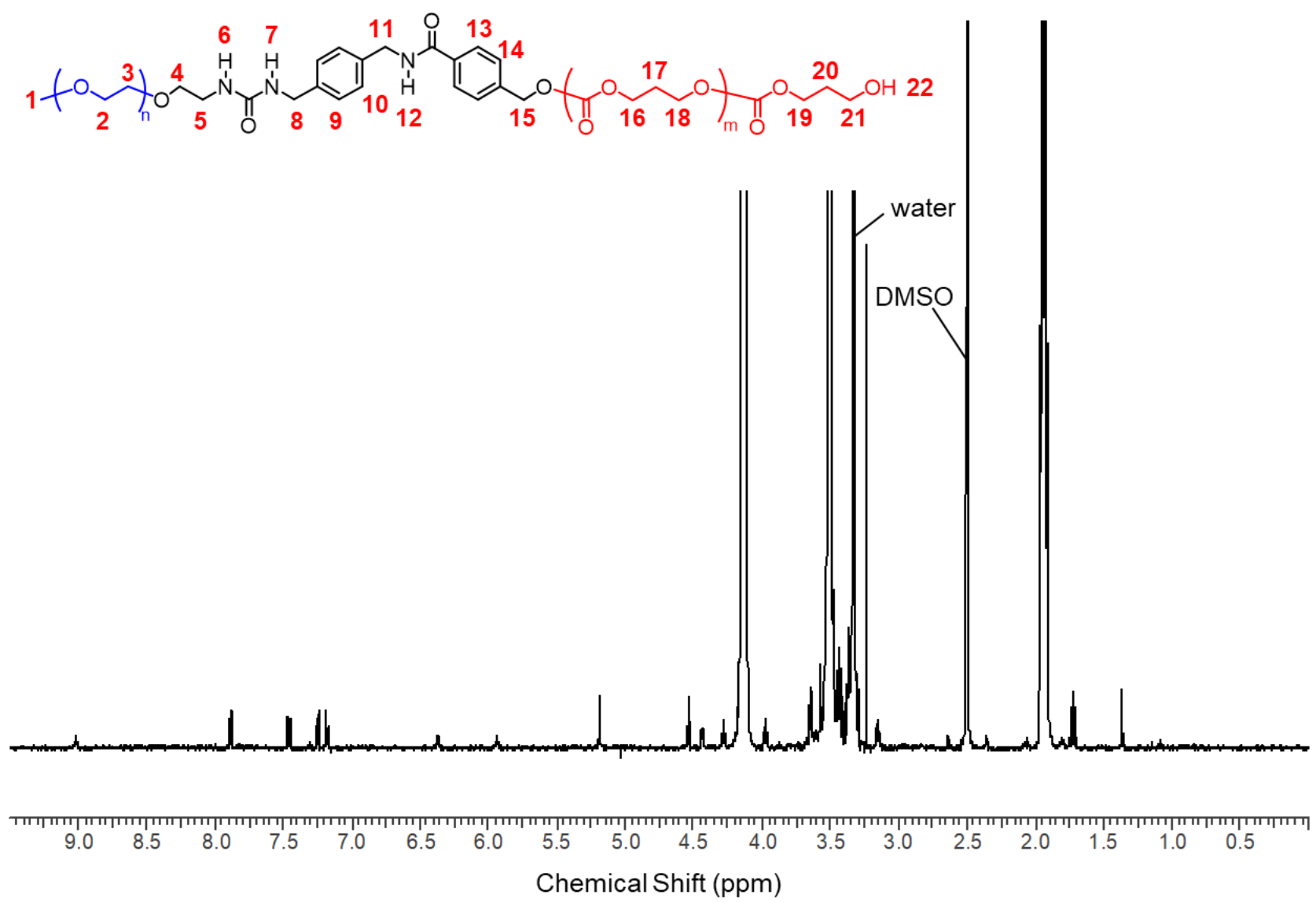


\section{References}

1. Pratt, R. C.; Lohmeijer, B. G. G.; Long, D. A.; Lundberg, P. N. P.; Dove, A. P.; Li, H.; Wade, C. G.; Waymouth, R. M.; Hedrick, J. L., Exploration, Optimization, and Application of Supramolecular Thiourea-Amine Catalysts for the Synthesis of Lactide (Co)Polymers. Macromolecules 2006, 39, 7863-7871.

2. Kim, S. H.; Nederberg, F.; Jakobs, R.; Tan, J. P. K.; Fukushima, K.; Nelson, A.; Meijer, E. W.; Yang, Y. Y.; Hedrick, J. L., A Supramolecularly Assisted Transformation of Block-Copolymer Micelles into Nanotubes. Angew. Chem. Int. Ed. 2009, 48, 4508-4512.

3. Fukushima, K.; Nozaki, K., Organocatalysis: A Paradigm Shift in the Synthesis of Aliphatic Polyesters and Polycarbonates. Macromolecules 2020, 53, 5018-5022.

4. Makiguchi, K.; Ogasawara, Y.; Kikuchi, S.; Satoh, T.; Kakuchi, T., Diphenyl Phosphate as an Efficient Acidic Organocatalyst for Controlled/Living Ring-Opening Polymerization of Trimethylene Carbonates Leading to Block, EndFunctionalized, and Macrocyclic Polycarbonates. Macromolecules 2013, 46, 1772-1782.

5. Makiguchi, K.; Satoh, T.; Kakuchi, T., Diphenyl Phosphate as an Efficient Cationic Organocatalyst for Controlled/Living Ring-Opening Polymerization of $\delta$-Valerolactone and $\varepsilon$-Caprolactone. Macromolecules 2011, 44, 1999-2005.

6. Lohmeijer, B. G. G.; Pratt, R. C.; Leibfarth, F.; Logan, J. W.; Long, D. A.; Dove, A. P.; Nederberg, F.; Choi, J.; Wade, C.; Waymouth, R. M.; Hedrick, J. L., Guanidine and Amidine Organocatalysts for Ring-Opening Polymerization of Cyclic Esters. Macromolecules 2006, 39, 8574-8583.

7. Nederberg, F.; Lohmeijer, B. G. G.; Leibfarth, F.; Pratt, R. C.; Choi, J.; Dove, A. P.; Waymouth, R. M.; Hedrick, J. L., Organocatalytic Ring Opening Polymerization of Trimethylene Carbonate. Biomacromolecules 2007, 8, 153-160.

8. Lin, B.; Waymouth, R. M., Organic Ring-Opening Polymerization Catalysts: Reactivity Control by Balancing Acidity. Macromolecules 2018, 51, 2932-2938.

9. Bayly, C. I.; Cieplak, P.; Cornell, W.; Kollman, P. A., A Well-Behaved Electrostatic Potential Based Method Using Charge Restraints for Deriving Atomic Charges: The Resp Model. J. Phys. Chem. 1993, 97, 10269-10280.

10. M. J. Frisch, G. W. T., H. B. Schlegel, G. E. Scuseria, M. A. Robb, J. R. Cheeseman, G. Scalmani, V. Barone, B. Mennucci, G. A. Petersson, H. Nakatsuji, M. Caricato, X. Li, H. P. Hratchian, A. F. Izmaylov, J. Bloino, G. Zheng, J. L. Sonnenberg, M. Hada, M. Ehara, K. Toyota, R. Fukuda, J. Hasegawa, M. Ishida, T. Nakajima, Y. Honda, O. Kitao, H. Nakai, T. Vreven, J. A. Montgomery Jr., J. E. Peralta, F. Ogliaro, M. Bearpark, J. J. Heyd, E. Brothers, K. N. Kudin, V. N. Staroverov, R. Kobayashi, J. Normand, K. Raghavachari, A. Rendell, J. C. Burant, S. S. Iyengar, J. Tomasi, M. Cossi, N. Rega, J. M. Millam, M. Klene, J. E. Knox, J. B. Cross, V. Bakken, C. Adamo, J. Jaramillo, R. Gomperts, R. E. Stratmann, O. Yazyev, A. J. Austin, R. Cammi, C. Pomelli, J. W. Ochterski, R. L. Martin, K. Morokuma, V. G. Zakrzewski, G. A. Voth, P. Salvador, J. J. Dannenberg, S. Dapprich, A. D. Daniels, Ö. Farkas, J. B. Foresman, J. V Ortiz, J. Cioslowski, D. J. Fox, Gaussian 09 Revision E.01. Gaussian, Inc.: Wallingford CT, 2009.

11. Wang, J.; Wolf, R. M.; Caldwell, J. W.; Kollman, P. A.; Case, D. A., Development and Testing of a General Amber Force Field. J. Comput. Chem. 2004, 25, 1157-1174.

12. Bussi, G.; Donadio, D.; Parrinello, M., Canonical Sampling through Velocity Rescaling. J. Chem. Phys. 2007, 126, 014101.

13. Berendsen, H. J. C.; Postma, J. P. M.; van Gunsteren, W. F.; DiNola, A.; Haak, J. R., Molecular Dynamics with Coupling to an External Bath. J. Chem. Phys. 1984, 81, 3684-3690.

14. Hess, B.; Bekker, H.; Berendsen, H. J. C.; Fraaije, J. G. E. M., Lincs: A Linear Constraint Solver for Molecular Simulations. J. Comput. Chem. 1997, 18, 1463-1472.

15. Essmann, U.; Perera, L.; Berkowitz, M. L.; Darden, T.; Lee, H.; Pedersen, L. G., A Smooth Particle Mesh Ewald Method. J. Chem. Phys. 1995, 103, 8577-8593.

16. Kawaguchi, S.; Imai, G.; Suzuki, J.; Miyahara, A.; Kitano, T.; Ito, K., Aqueous Solution Properties of Oligo- and Poly(ethylene oxide) by Static Light Scattering and Intrinsic Viscosity. Polymer 1997, 38, 2885-2891.

17. Benoit, H.; Doty, P., Light Scattering from Non-Gaussian Chains. J. Phys. Chem. 1953, 57, 958-963.

18. Suzuki, Y.; Watanabe, T.; Kosugi, H.; Ueda, K.; Kikuchi, M.; Narumi, A.; Kawaguchi, S., Chain Conformation of Poly(D-lactide) in Tetrahydrofuran by Static Light Scattering, Small-Angle X-Ray Scattering, and Intrinsic Viscosity. Macromolecules 2020, 53, 1604-1612.

19. Semenov, A. N.; Nyrkova, I. A.; Khokhlov, A. R., Polymers with Strongly Interacting Groups: Theory for Nonspherical Multiplets. Macromolecules 1995, 28, 7491-7500.

20. Marrink, S. J.; Risselada, H. J.; Yefimov, S.; Tieleman, D. P.; de Vries, A. H., The MARTINI Force Field: Coarse Grained Model for Biomolecular Simulations. J. Phys. Chem. B 2007, 111, 7812-7824.

21. Yamamoto, T., Molecular Dynamics of Polymer Crystallization Revisited: Crystallization from the Melt and the Glass in Longer Polyethylene. J. Chem. Phys. 2013, 139, 054903. 
22. Tsuzuki, S.; Honda, K.; Uchimaru, T.; Mikami, M.; Tanabe, K., The Magnitude of the $\mathrm{CH} / \pi$ Interaction between Benzene and Some Model Hydrocarbons. J. Am. Chem. Soc. 2000, 122, 3746-3753.

23. Maeda, T.; Fujime, S., Spectrum of Light Quasielastically Scattered from Solutions of Very Long Rods at Dilute and Semidilute Regimes. Macromolecules 1984, 17, 1157-1167.

24. Kubota, K.; Urabe, H.; Tominaga, Y., Spectrum of Light Quasi-Elastically Scattered from Suspensions of Tobacco Mosaic Virus. Experimental Study of Anisotropy in Translational Diffusion. Macromolecules 1984, 17, 2096-2104.

25. Newman, J.; Swinney, H. L., Length and Dipole Moment of TMV by Laser Signal-Averaging Transient Electric Birefringence. Biopolymers 1976, 15, 301-315.

26. Suzuki, Y.; Sakai, N.; Yoshida, A.; Uekusa, Y.; Yagi, A.; Imaoka, Y.; Ito, S.; Karaki, K.; Takeyasu, K., High-Speed Atomic Force Microscopy Combined with Inverted Optical Microscopy for Studying Cellular Events. Sci. Rep. 2013, 3, 2131.

27. Osada, E.; Suzuki, Y.; Hidaka, K.; Ohno, H.; Sugiyama, H.; Endo, M.; Saito, H., Engineering RNA-Protein Complexes with Different Shapes for Imaging and Therapeutic Applications. ACS Nano 2014, 8, 8130-8140.

28. Farah, S.; Anderson, D. G.; Langer, R., Physical and Mechanical Properties of PLA, and Their Functions in Widespread Applications - A Comprehensive Review. Adv. Drug Delivery Rev. 2016, 107, 367-392.

29. Pêgo, A. P.; Grijpma, D. W.; Feijen, J., Enhanced Mechanical Properties of 1,3-Trimethylene Carbonate Polymers and Networks. Polymer 2003, 44, 6495-6504. 